\title{
Robust design of flash evaporators for must concentration applications in wine production
}

\author{
Thomas Quirante, Yann Ledoux*, and Patrick Sebastian \\ Université de Bordeaux, I2M, UMR 5295, 33400 Talence, France
}

Received: 23 March 2016 / Accepted: 4 May 2018

\begin{abstract}
In recent years, flash evaporation processes have received an increased attention in the wine industry for must concentration applications. Specific constraints related to the wine industry area had lead to many improvements of flash evaporators initially designed for seawater desalination. In particular the quality of the vintage, the transportability of the system and the environmental impact are of main interest. Moreover, the preliminary design of such systems must also consider robustness criteria. Obviously, variations of temperatures and flow rates of liquids at the inlet of the process can dramatically impact the quality of the product at the system outlet. In particular, deviations from the target values of temperature and alcoholic volume fraction can lead to a severe degradation of the vintage. As it is common in product design to have multiple performance measures, the robust design problem is addressed using a multi-objective approach. A trade-offs is introduced between two main design objectives: (i) the improvement in overall performance (product quality, transportability, environmental impact and costs) and (ii) the lowering of the sensitivity of the product quality under uncertainty. These main objectives are related to several elementary objectives corresponding to design criteria and a preference aggregation method is used to formulate the two different design objectives. Objectives are linked to weighting parameters values equivalent to priority levels. The selection of the most preferred design solution is discussed according to different trade-off strategies. The generation of the Pareto set is addressed by the non dominated sorting genetic algorithm NGSAII. From computing results, our recommendations concern the compromise between performance and robustness of flash evaporators. In this context, the final alcoholic volume fraction of the wine is the most sensitive parameter, which justify to maintain a high value of evaporative capacity when designing this type of system.
\end{abstract}

Keywords: Flash evaporation / robustness / desirability function / trade-off / non dominated sorting genetic algorithm

\section{Introduction}

In recent years, flash evaporation processes have received an increased attention in many different domains of concentration processes such as desalination of water [1]. Concerning food engineering, a general overview of flash processes could be seen in [2] where several applications like flash distillation or milk treatment (pasteurization or sterilization) are developed. For fruit juices Ruan proposes in [3] a mathematical model for multiple stages of flash evaporation. In the wine industry a review of main extraction processes is proposed in [4] including flash evaporation processes. Due to a drop of the table wine consumption and changes of consumer tastes, there is a growing interest in using flash evaporation processes in the wine industry. Indeed, according to specific studies for the

\footnotetext{
* e-mail: yann.ledoux@u-bordeaux.fr
}

pre-treatment of grapes by flash-release (or flash détente), benefits come from considerable improvements of the wine quality and enhancement of its gustative properties [5-7]. In particular, the final content of polyphenol in the wine (chemical agent in the berries skin tissues responsible for the colour and flavour of red wines) is at least $50 \%$ higher compared to wines obtained from traditional production techniques [8].

Figure 1 shows the must concentration by flash evaporation within the wine production process. This operation consists in increasing the alcoholic volume fraction of the must until the final desired value. As a general rule, an enrichment of $1 \%$ by volume required to evaporate $10 \%$ of the vintage volume. Typically, grapes are first heated at temperatures ranging between $70^{\circ} \mathrm{C}$ to $90^{\circ} \mathrm{C}$ according to traditional postharvest process [9]. The vintage is then brutally cooled by flash evaporation to temperatures ranging between $25^{\circ} \mathrm{C}$ to $30^{\circ} \mathrm{C}$ which are suitable for vintage fermentation. The terminology flash 


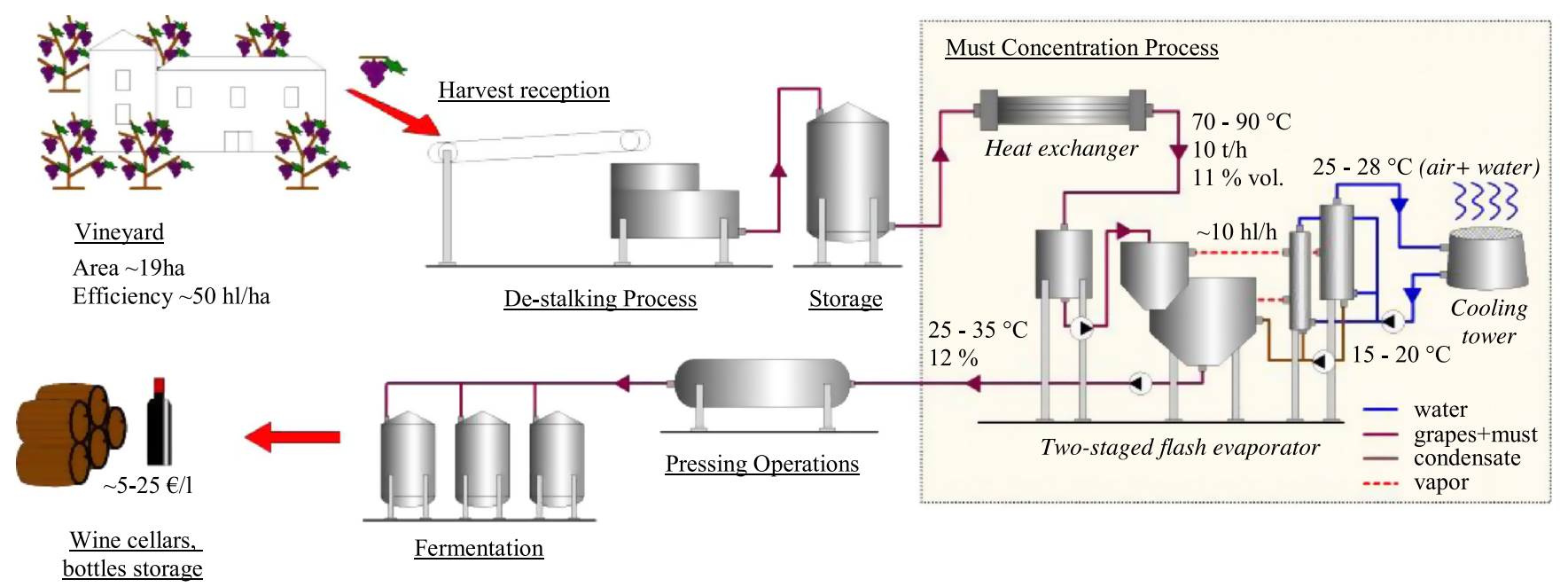

Fig. 1. Must concentration by flash evaporation in the wine production process.

comes from the quasi-instantaneous and partial vaporization of the vintage when it is subjected to a sudden drop of pressure below its saturation pressure [10]. As a consequence, the liquid temperature drops to the saturation temperature corresponding to the lowered pressure. Additionally, due to this abrupt change of pressure, sudden mechanical constraints appear within berry skin tissues, enhancing the release of many different substances such as tannins, and thus, improve the color and some gustative properties of wines.

In practical terms, specific constraints related to the wine industry area had lead to many improvements of flash evaporators initially designed for seawater desalination [11] and flavors extraction [12] applications. Typical flash evaporators must be designed to treat grape mass flow rate of at least $10 \mathrm{t} / \mathrm{h}$ which corresponds to the treatment of the whole harvest of an average vineyard of 19 ha, with a production efficiency of $50 \mathrm{hl} / \mathrm{ha}$ in the region of Bordeaux [13], during a working day $(\sim 10 \mathrm{~h})$. This requirement often leads to oversized systems while flash evaporators are required to be transportable from a wine production site to another during the harvest period. But, the main weakness of this system is its high energy consumption impacting the environment and increasing considerably the operating costs, and so the price of wine (given in $€ / 1$ of wine). Indeed, thermal and electrical energy (defined in $\mathrm{kW} \cdot \mathrm{h} / \mathrm{hl}$ of wine) are required respectively to heat the vintage at the inlet of the evaporator, and to supply pumps for liquids circulation and fan for the warm air in the cooling tower (cf. Fig. 1). The water consumption of the system is due to the evaporation of the water required to condensate the vapors within the condensers while it goes through the cooling tower. Based on this considerations, the system designed by Sebastian et al. [12,14] is based on the development of a two-staged evaporator combined with the used of compact condensers and mist eliminators. The main components of this process and the industrial system have already been presented in $[15,16]$.

In a recent study, the formulation of the model was proposed by [17]. In [18], we tackled the preliminary design of this flash evaporator by trading-off multiple conflicting design objectives of performance such as transportability, environmental impact, operative cost, product quality and cooling power. A multi-objective optimization (MO) method based on preferences formulation with desirability functions is proposed to investigate the design space, and thus, determine the most preferred solution. However, this approach still cannot be considered completely satisfactory since we processed a nominal optimization without taking into account the inherent variability of operating conditions and environmental parameters (uncertainties) that may disturb the nominal performances of the system. Obviously, variations of temperatures and flow rates of liquids (must and water) at the inlet of the process can dramatically impact the quality of the product at the system outlet. In particular, deviations from the target values of temperature and alcoholic volume fraction can lead to a severe degradation of the vintage. These two parameters are definitively decisive for the final wine quality and thus, their variations must be controlled.

The purpose of this research work is to determine an optimal robust design for the two-staged flash evaporator previously discussed. A design is called robust if it achieves simultaneously a satisfying level of performance and low sensitivity under uncertainty. Robust design methodologies are widely used in engineering to improve the quality of products and processes [19]. As the reduction of the overall degree of uncertainty impacting the systems performances is often impossible, robust design aims at designing systems that are relatively insensitive to variability and imprecision. Most of the time, the system quality is estimated through a quality loss function [20,21]. The "parameters design" method proposed by Taguchi [21] aims at determining the design parameters values while variability is considered. In this way, he introduced a "signal-to-noise" ratio to evaluate the robustness of each candidate solution, expressed as:

$$
\eta=-10 \log \left(\frac{y}{\sigma}\right),
$$

where $y$ and $\sigma$ denote respectively the mean and the standard deviation of the performance. Many robust 


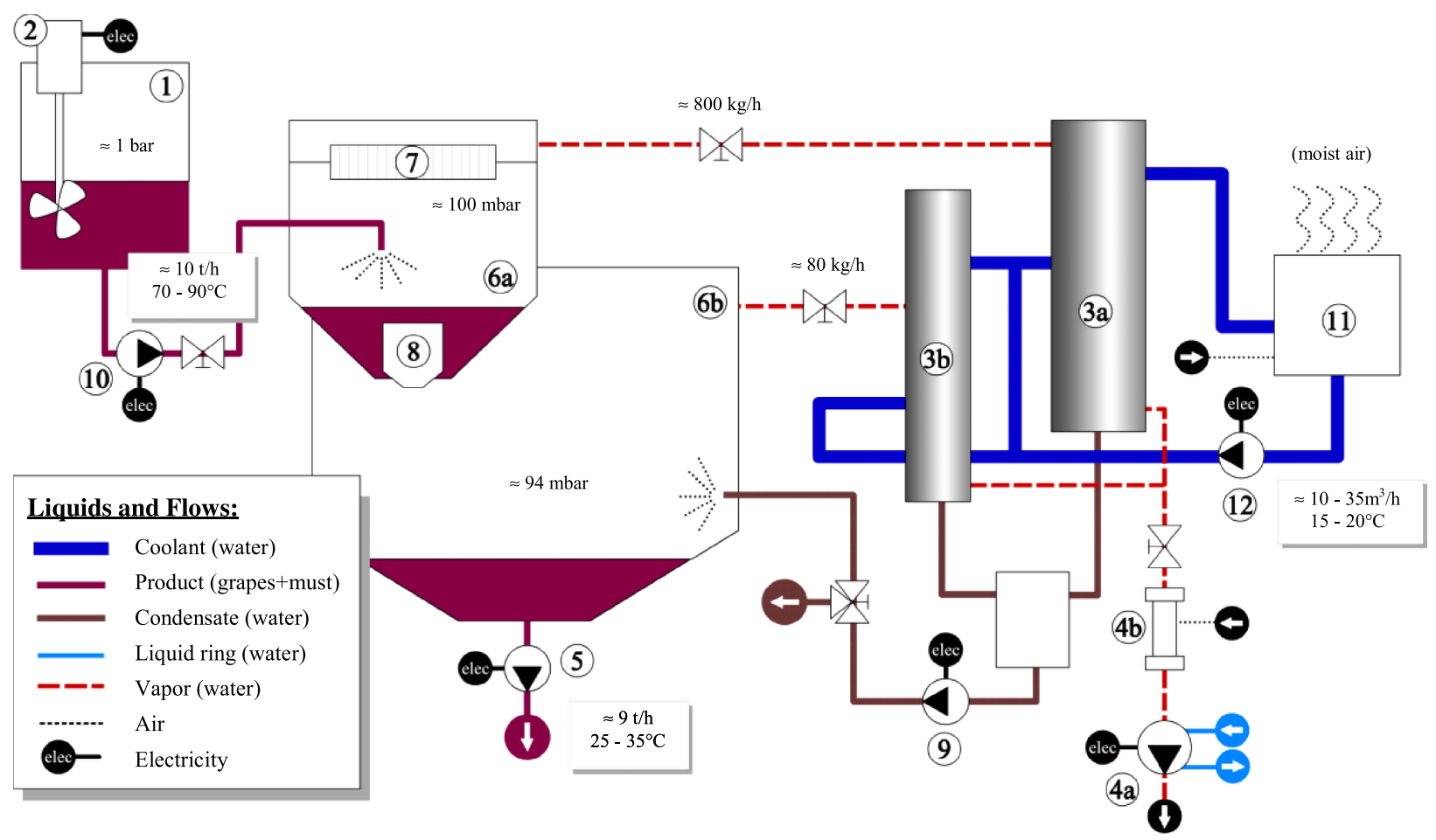

Fig. 2. Two-stage flash evaporator principles.

optimization approaches based on the calculation of these two measures have been developed in the past few years. It can be cited the work of Brotchie in [22] optimizing a structural optimization or Parkinson in [23] applying same procedure in general analytical problem. Du in [24] introduce the probabilistic approach in design formulation and Ardakani in [25] has proposed to compare different strategies based on mean and standard deviation quantifications. A review of the different existing robust optimization methods can be found in the litterature. A general overview is available in [26] or in [27]. The works of Arvidsson [28] or of Schuëller [29] are more dedicated to analyze computation methods for the robust design. However, the interpretation of the performance mean and standard deviation are sometimes difficult in presence of non-Gaussian distributions.

As it is common in product design to have multiple performance measures, robust design is often addressed using a MO approach like in [30] or in [31]. Basseur in [32] or Greiner [33], have introduced uncertainties into multiobjective optimization. In a recent study [34], we proposed to formulate the sensitivity of the design as a particular design objective to be traded-off. However, this approach doesn't allow designers to express a compromise between the performance and the sensitivity while, these objectives must be obviously balanced according to the designers' expectations.

In this paper, we address the robustness of the flash evaporator as a trade-off between two design objectives: (i) the improvement in overall performance (efficiency, transportability, environmental impact, costs) and (ii) the lowering of the sensitivity of the product quality under uncertainty. Three objectives measures are proposed to observe the dispersion of the performances: the bandwidth of variation, the tolerance to nominal, and the minimum admissible value. No assessments are made on the distribution of noise factors (temperatures and flow rates). A preference aggregation method is used to formulate the two design objectives. The selection of the most preferred design solution is discussed according to different trade-off strategies and scenarios. The design objective linked to the product quality has been modified to integrate the enhancement of gustative properties and the rate of must concentration. The generation of the Pareto set is addressed by the non dominated sorting genetic algorithm NGSAII.

\section{Two-staged flash evaporation process and design model}

This paragraph aims at introducing briefly the principles of the two-stage flash evaporator, and at characterizing the main variables associated to the design of the system.

\subsection{Principles}

The two-staged flash evaporator represented in diagram form in Figure 2 is designed to treat about $10 \mathrm{t} / \mathrm{h}$ of grapes. The vintage is initially heated at temperatures ranging between $70^{\circ} \mathrm{C}$ to $90^{\circ} \mathrm{C}$ under atmospheric conditions, and stored in the buffer tank (1) where it is stirred by a mixer (2) to maintain a uniform temperature. The system is put under vacuum conditions due to the action of a vacuum pump (4a) coupled with an air ejector (4b). A pump makes the fluid to be sucked up the low-pressure stage of the evaporation chamber. As soon as the product enters in the 
Table 1. Design variables and associated domain of values.

\begin{tabular}{|c|c|c|c|c|c|}
\hline Design variables $\boldsymbol{x}=\left[x_{1}, \ldots, x_{6}\right]^{\mathrm{T}}$ & Name & Unit & \multicolumn{3}{|c|}{ Domain $\Omega(X)=\left[x_{-;} x_{+}\right]$} \\
\hline Inlet product temperature $\left(x_{1}\right)$ & $T_{p i}$ & ${ }^{\circ} \mathrm{C}$ & 70 & 90 & Continuous \\
\hline Inlet coolant temperature $\left(x_{2}\right)$ & $T_{c l}$ & ${ }^{\circ} \mathrm{C}$ & 15 & 25 & Continuous \\
\hline Inlet coolant flow rate $\left(x_{3}\right)$ & $q_{c l}$ & $\mathrm{t} / \mathrm{h}$ & 1 & 20 & Continuous \\
\hline Flow rate of the coolant added to the low-pressure condenser $\left(x_{4}\right)$ & $\mathrm{q}_{\mathrm{cl}+}$ & $\mathrm{t} / \mathrm{h}$ & 1 & 25 & Continuous \\
\hline Number of plates in the very low-pressure condenser $\left(x_{6}\right)$ & $N_{V L P}$ & - & 6 & 250 & Discrete \\
\hline
\end{tabular}

low pressure (LP) expansion chamber (6a), a part of the liquid phase is suddenly vaporized, and the level of the remaining fluid rises and activates the float (8) to maintain the pressure difference between the stages. Entering in the very-low pressure (VLP) stage (6b) of the evaporation chamber, the fluid is then once again partially vaporized. The remaining part of the fluid is extracted by the extraction pump (5) which is an eccentric rotor pump of the Archimedes screw type. This type of pump is well adapted for moving fluids containing solid particles such as grapes.

The vapor created by the fluid evaporation is condensed through two condensers, one for each stage $(3 \mathrm{a}, 3 \mathrm{~b})$, to maintain in the system under low pressure conditions. Condensates are stored in a tank from where they are extracted by a condensate pump (9). As the vaporization at the low-pressure stage is very violent, droplets are formed and carried out with the vapor. Therefore, a mist eliminator (7) is added to ensure the droplet recovery. The cooling of vapors within the condensers is maintained by the joint action of a mechanical draft cooling tower (11) coupled with a centrifugal pump (12).

The transfers, dimensional, environmental and economical models contributing to the design model of the flash evaporation process are not detailed in this paper, but the reader could refer to [15-17] for further explanations.

\subsection{Definition of design variables}

Modeling of flash evaporator design problems requires the definition of the design variables $(\boldsymbol{x})$. Such variables are the main dimensioning and monitoring parameters required to completely define the system (regarded as a candidate solution) and its functioning environment (vintage and coolant liquid). They refer to the inlet temperature $\left(T_{p i}\right)$ of the product (must and grapes), the inlet temperature $\left(T_{c l}\right)$ and flow rate $\left(q_{c l}\right)$ of the coolant liquid (water), the flow rate $\left(q_{c l+}\right)$ of the coolant added to the LP condenser, and finally, the number of plates in the low-pressure $\left(N_{L P}\right)$ and very low-pressure $\left(N_{V L P}\right)$ condensers. Condensers can be composed up to 250 plates which represents a maximal heat surface exchange of $40 \mathrm{~m}^{2}$ by condenser. As the flash evaporator is supposed to be designed to treat $10 \mathrm{t} / \mathrm{h}$ of grapes, the inlet product flow rate is considered here as a constant parameter of the design model.

Design variables are provided with admissible domains of values, generating the so called design space $(\Omega)$ to be investigated. The ranges of design variables values are provide in Table 1. As a set of design variable values characterizes one particular candidate solution, different combinations of design variables values lead to flash evaporators with different levels of performance.

\subsection{Performance and observation variables}

Performances of two-staged flash evaporator are observed through a set of observation variables. They are suitable measures of some system properties, required to support the decision making process. The discrimination of design alternatives is based on the evaluation and comparison of their ability in meeting simultaneously every design criteria, i.e. equality or inequality constraints associated with observation variables. Moreover, every criterion and so, observation variable, can be associated to the achievement of the following design objectives of performance: improving the quality of the product, improving the system transportability, reducing the environment impact of the system and reducing the overall total cost.

\subsubsection{Quality of the product}

Due to the importance of preserving the gustative properties of wine while meeting international and regional legislations of the wine-making practices, the quality of the product (i.e. grapes and must) at the outlet of the flash evaporator is the first design objective to be considered. The quality of the product depends both on the temperature, the level of final alcoholic volume fraction and the rate of polyphenol of vintage at the outlet of the system. The temperature of the product at the outlet of the flash evaporator $\left(T_{p o}\right)$ is equal to the saturation temperature of the vapor inside the VLP stage of the evaporation chamber. Depending on the type of wine expected, the desired target temperature can slightly vary from one producer to another. But, in general, the continuity and efficiency of the fermentation process is ensured for temperatures comprised between $10^{\circ} \mathrm{C}$ (the temperature below is too low for the yeast to work in the fermentation process) and $35^{\circ} \mathrm{C}$ (die of the yeast).

The rate of concentration $(C x)$ of the product is the ratio between the mass flow rate of water evaporated during the process and the initial mass flow rate of product:

$$
C x=\frac{q_{\text {vapor }}}{q_{p i}}=\frac{\left(q_{p i}-q_{p o}\right)}{q_{p i}}
$$


where $q_{p i}$ and $q_{p o}$ are respectively the input and output product flow rate, $q_{\text {vapor }}$ is the mass flow rate of water eliminated during the process. The rate of concentration determines the evaporative capacity of the system. The mass flow rate of water to be eliminated, and so, the rate of concentration, are constrained by the desired final alcoholic volume fraction of the must. In general, it is estimated using the following formula [35]:

$$
q_{v a p o r}=q_{p i}-q_{p o} \quad \text { with } \quad q_{p o}=q_{p i} \cdot \frac{D_{p i}}{D_{p o}}
$$

where $D_{p i}$ and $D_{p o}$ are respectively the initial and final alcoholic volume fraction of the must. For example, increasing the alcoholic volume fraction from $11 \%$ to $12.5 \%$ by volume, of $100 \mathrm{hl}$ of must, implies a vaporization of $12 \mathrm{hl}$ of water.

As the release of tannins and polyphenol mainly depends on the drop of pressure in the expansion chambers, and according to the results presented in [8], we considered here that the pressure inside the very low pressure chamber must be at least of 94 mbar.

\subsubsection{Transportability}

As mentioned in the introduction, the transportability of the system is a significant design objective since it must be moved from one wine production site to another during the harvest period. The transportability depends both on the floor area $\left(A_{\text {sys }}\right)$ and the overall mass $\left(m_{\text {sys }}\right)$ of the system which must not exceed a limit defined by the standard maximal capacities of flat bed trucks. It is estimated by calculating the mass and size of tanks (expansion chambers, buffer and condensates tanks), condensers and pumps which are the biggest and heaviest components of the system. The total mass of the system also involves the mass of the metallic structure used to support the flash evaporator.

$$
\begin{aligned}
& m_{\text {sys }}=m_{\text {tanks }}+m_{\text {condensers }}+m_{\text {pumps }}+m_{\text {structure }} \\
& A_{\text {sys }}=A_{\text {tanks }}+A_{\text {condensers }}
\end{aligned}
$$

\subsubsection{Environmental impact}

Facing with the emergence of environmental constraints in the agricultural field, the environmental impact of the flash evaporation process must be also considered as a design objective. One of the main inconvenient of flash evaporation processes is its high consumption of energy, materials and fluids. In this study, the material consumption of the system is mainly based on the total mass of steel used for manufacturing the tanks. Based on the EcoIndicator99 methodology [36], the relative impact corresponding to 1 ton of steel is quantified and the related damage coefficients (environment, human health, resources) are derived.

$$
\begin{gathered}
E I_{\text {material }}=\left(a_{1}+a_{2}+a_{3}\right) \cdot m_{\text {sys }} \\
t a_{1}=1.9(\text { environment }), a_{2}=13233(\text { humanhealth }), \\
a_{3}=2.3(\text { resources })
\end{gathered}
$$

Similarly, we evaluate the damage coefficients associated to the consumptions of $10 \mathrm{~kW} \cdot \mathrm{h}$ and $1 \mathrm{~m}^{3}$ of water. Finally, a global score $E I$ is derived from the impacts of material, energy and water consumptions.

with,

$$
E I=E I_{\text {material }}+E I_{\text {elec }}+E I_{\text {water }}
$$

$$
\begin{aligned}
& E I_{\text {elec }}=\left(b_{1}+b_{2}+b_{3}\right) \cdot C_{\text {elec }}, b_{1}=0.145 \\
& b_{2}=0.0139, b_{3}=0.0271 \\
& \begin{aligned}
E I_{\text {water }} & =\left(c_{1}+c_{2}+c_{3}\right) \cdot C_{\text {water }}, c_{1} \\
& =0.0187, c_{2}=0.00204, c_{3} \\
& =0.00607
\end{aligned}
\end{aligned}
$$

The energy consumption calculation is based on the power required to supply the different pumps, mixer and fan. The water consumption corresponds to the mass flow rate of water used by the cooling tower. Mechanical draft cooling towers consume water in three major ways [37]. Evaporation rate $\left(\mathrm{C}_{E}\right)$ is approximately $1 \%$ of the water flow rate per each $10^{\circ} \mathrm{F}\left(\approx 5.5^{\circ} \mathrm{C}\right)$ of the cooling range. Drift $\left(C_{D}\right)$ is approximately $0.2 \%$ of the water flow rate, and refers to the water which leaves the cooling tower carried out with the exiting air. In order to prevent concentration of solid and chemical particles in the cooling water resulting from the evaporation, blowdown $\left(C_{B}\right)$ is the mass of water removed from the system and replaced by fresh water. It is usually $20 \%$ of the evaporation rate.

$$
\begin{aligned}
& C_{\text {elec }}=\left(\text { Power }_{\text {mixer }}+\text { Power }_{\text {fan }}+\sum \text { Power }_{\text {pumps }}\right) \cdot t_{o p} \\
& C_{\text {water }}=\left(C_{E}+C_{D}+C_{B}\right) \cdot t_{\text {op }}
\end{aligned}
$$

The electrical consumption and water consumption are respectively expressed in $\mathrm{kW} \cdot \mathrm{h}$ and $\mathrm{t} / \mathrm{h}$. They are estimated over a period of 20 years with an average operating time of $10 \mathrm{~h}$ a day during 2 months (duration of the harvest period).

\subsubsection{Total cost}

The development of flash détente processes in the wine area is also hampered by the initial cost of investment. The economical analysis of the flash evaporator aims at modeling manufacturing costs (material purchase and forming) of tanks, and purchasing costs of other parts of the flash evaporation system (condensers, pumps, etc.). The global purchasing cost of the system is calculated by adding these manufacturing and purchasing costs for each part of the system. The total investment $\left(C_{\text {invest }}\right)$ cost of the process results from this global purchasing cost multiplied by the Lang factor to take into account installation costs, transportation costs and various costs such as insurance [38].

From the investment cost of the system, we derive the maintenance cost which is assessed as 2.5 per cent of the investment cost, and the total discounting cost of the system which is estimated from the coefficient of discounting evaluated over a period of twenty years. The overall operating $\operatorname{cost}\left(C_{o p}\right)$ over this period is derived from the electricity and water consumption costs calculated 

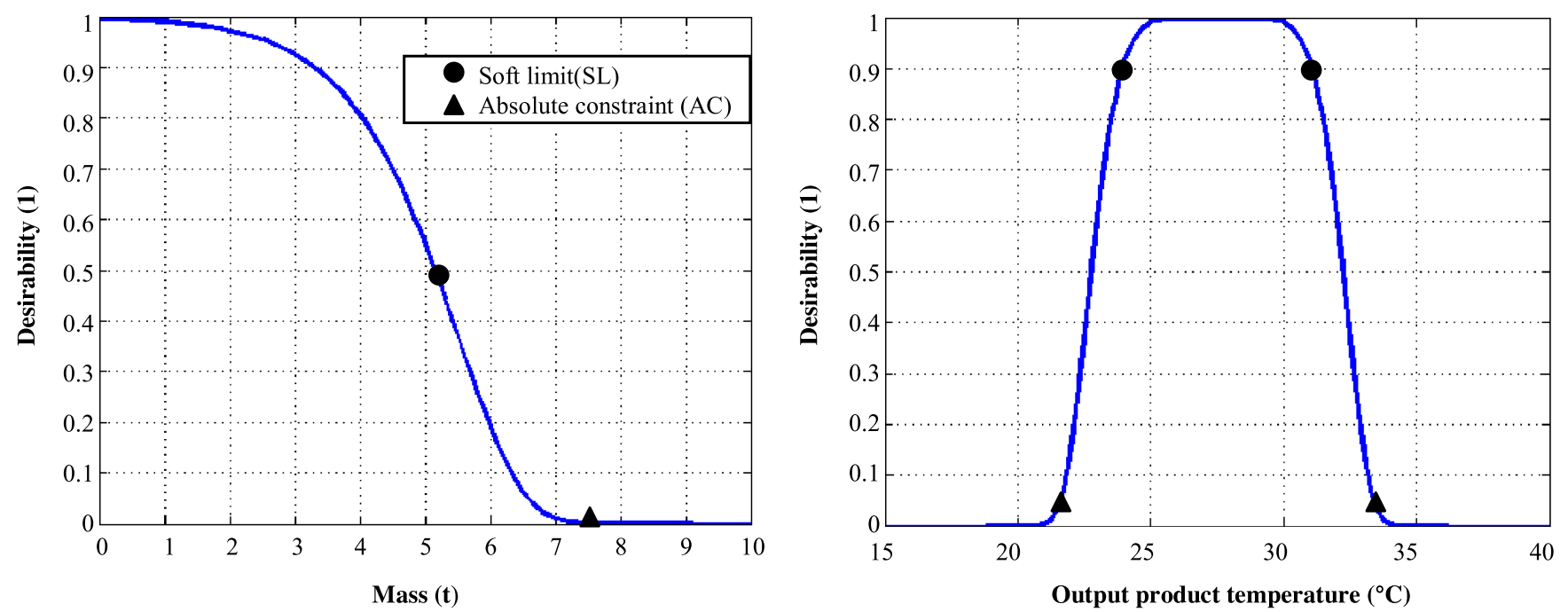

Fig. 3. Desirability functions for the mass and the output temperature.

according to the peak charges applied by EDF $(0.1275 €$ / $\mathrm{kW} \cdot \mathrm{h})$ and the average price of water distributed in France $\left(3.39 € / \mathrm{m}^{3}\right)$ in 2011 . Finally, the overall total cost $\left(C_{\text {total }}\right)$ is calculated by adding the overall costs of discounting and the operating cost of the system.

\section{Expression of performance objective through desirability}

The approach based on the concept of desirability and developed for modeling the preference and optimizing the design architecture had already been presented by Sebastian et al. [18].

\subsection{Desirability functions and criteria}

Desirability functions are value functions mapped between zero and one, which enable to bring the observation variables on a same scale of values. They allow the designer to model preferences on the criteria satisfaction, and thus, enhance the design model with non-formalized expert knowledge. Harrington's desirability functions [39] are declined into one-sided type or two-sided type depending if the property is expected to be minimized (or maximized) or if a target value is desired. The specification of these functions requires at least four parameters which are the desirability and threshold values associated to the definition of an absolute constraint (AC) and a soft limit (SL). Absolute constraints specification usually corresponds to the criteria expressed in the requirements. In this study, the soft limits related to transportability and cost criteria are derived from a system of reference with intermediate performance, i.e. associated with a global desirability of 0.5 .

The system of reference is a mono-stage evaporator proposed by the society "Entropie SAS". It had been chosen to concentrate $10 \mathrm{t} / \mathrm{h}$ of product from $11 \%$ to $12 \%$ by volume which corresponds to an evaporative capacity of $1 \mathrm{t} / \mathrm{h}$ of water. From the constructor data, we evaluate the weight and floor occupation of this system respectively equal to $5.3 \mathrm{t}$ and $10 \mathrm{~m}^{2}$, for an estimated cost of investment of close to $153 \mathrm{k} €$. The criteria related to the product quality are mainly turned into target objectives. As an example, the desirability functions associated to the mass and output temperature criteria are plotted in Figure 3. Criteria and desirability function specifications used in this study are given in Table 2 .

\subsection{Design objective of performance}

Individual desirability functions are then aggregated into design objective indices (DOI), and finally, into a global desirability index (GDI) of performance as follow:

$$
\begin{aligned}
& G D I_{\text {perfo }}=\prod_{i=1}^{4} D O I_{i} w_{i}, \quad w=[0.5,0.3,0.1,0.1]^{T} \\
& \text { with } D O I_{1}=d_{1}{ }^{1 / 3} d_{2}{ }^{1 / 3} d_{3}{ }^{1 / 3}, \quad D O I_{2}=d_{4}{ }^{1 / 2} d_{5}{ }^{1 / 2} \text {, } \\
& D O I_{3}=d_{6}{ }^{1}, \quad D O I_{4}=d_{7}{ }^{1 / 2} d_{8}{ }^{1 / 2}
\end{aligned}
$$

These values qualify the level of achievement for each design objective. The aggregation function is the weighted geometric mean as proposed by Derringer [40]. This aggregation function presents mathematical properties which are relevant in a design context. According to the axioms of the Method of Imprecision (MoI) developed by Anthonsson [41], this aggregation function is said to be design appropriate [42]. In particular, the axiom of annihilation states that the result of the aggregation must be equal to zero if at least one of the desirability values equals zero. The definition of an aggregation function also includes the definition of a weight vector $\boldsymbol{w}$ to express priority orders between objectives. Multicriteria decision methods such as Saaty's Analytic Hierarchy Process (AHP) [43] can be used as basis for the numerical weights assignment.

The global formulation of the performance design objective is summarized in graph form in Figure 4. The simulation model, desirability and aggregation functions 
Table 2. Desirability function specifications.

\begin{tabular}{|c|c|c|c|c|c|c|c|c|}
\hline \multirow[t]{2}{*}{$\begin{array}{l}\text { Design objectives } \\
\boldsymbol{D O} \boldsymbol{I}=\left[D O I_{1}, \ldots, D O I_{4}\right]^{\mathrm{T}}\end{array}$} & \multirow[t]{2}{*}{$\begin{array}{l}\text { Observation var. } \\
\boldsymbol{y}=\left[y_{1}, \ldots, y_{8}\right]^{\mathrm{T}}\end{array}$} & \multirow[t]{2}{*}{ Name } & \multirow[t]{2}{*}{ Unit } & \multicolumn{5}{|c|}{$\begin{array}{l}\text { Desirability functions specifications } \\
\boldsymbol{d}=\left[d_{1}, \ldots, d_{8}\right]^{\mathrm{T}}\end{array}$} \\
\hline & & & & $\mathrm{AC}$ & $\mathrm{d}(\mathrm{AC})$ & $\mathrm{SL}$ & $\mathrm{d}(\mathrm{SL})$ & Objective \\
\hline \multirow{6}{*}{ 1) Product quality } & \multirow[t]{2}{*}{ Product output temperature } & \multirow[t]{2}{*}{$T_{p o}$} & \multirow[t]{2}{*}{$\left({ }^{\circ} \mathrm{C}\right)$} & 20 & 0.05 & 25 & 0.9 & \multirow[b]{2}{*}{ Target } \\
\hline & & & & 35 & 0.05 & 30 & 0.9 & \\
\hline & Alcoholic volume fraction & $D_{p o}$ & $(\%)$ & 11 & 0.05 & 11.8 & 0.9 & \multirow[b]{2}{*}{ Target } \\
\hline & & & & 13 & 0.05 & 12.2 & 0.9 & \\
\hline & Pressure & $P_{V L P}$ & (mbar) & 97 & 0.01 & 94 & 0.9 & Minimize \\
\hline & Mass & $m_{\text {sys }}$ & (t) & 7.5 & 0.01 & 5.3 & 0.5 & Minimize \\
\hline 2) Transportability & Floor area & $A_{\text {sys }}$ & $\left(\mathrm{m}^{2}\right)$ & 16 & 0.01 & 10 & 0.5 & Minimize \\
\hline 3) Environmental impact & Eco-Indicator & $E I_{g g}$ & $(-)$ & 50000 & 0.01 & 1000 & 0.99 & Minimize \\
\hline \multirow{2}{*}{ 4) Cost } & Investment Cost & $C_{\text {invest }}$ & $(\mathrm{k} €)$ & 465 & 0.01 & 141 & 0.5 & Minimize \\
\hline & Operating costs & $C_{o p}$ & $(\mathrm{k} €)$ & 153 & 0.01 & 84 & 0.5 & Minimize \\
\hline
\end{tabular}

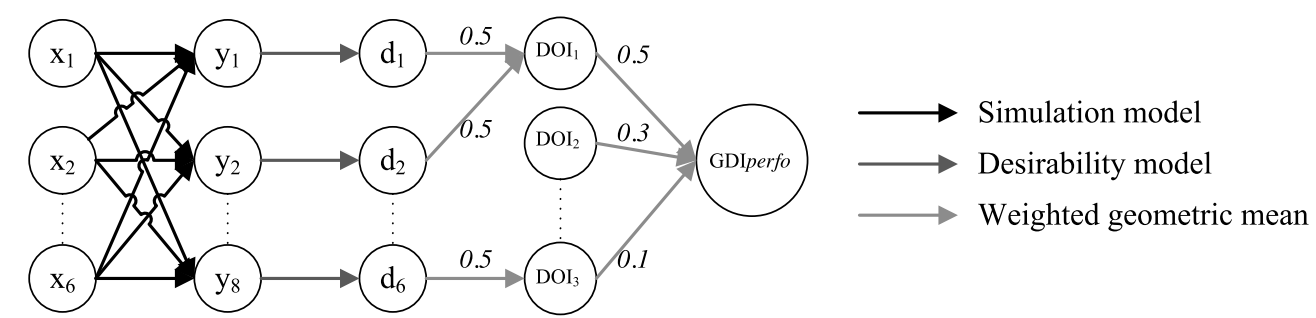

Fig. 4. Formulation of the performance design objectives.

are highlighted in different colors. The numerical weights involved in the aggregation processes are reported in italic font.

\section{Uncertainties and design objective of sensitivity}

Due to the inherent uncertainty and external fluctuations of the operating conditions, performances are often disturbed from their nominal predictive values. In this study, a design is said to be robust if it presents simultaneously a satisfying level of overall performance and a low variability of the vintage quality. It entails the minimization of the dispersion of the vintage outlet temperature $\left(y_{1}\right)$, final alcoholic volume fraction $\left(y_{2}\right)$ and pressure inside the VLP chamber $\left(y_{3}\right)$ around their nominal values under uncertainty. In the following, we denote as nominal, the value of a variable (or a parameter) without taking any uncertainty into account.

\subsection{Uncertainty modeling}

The robust design of flash evaporators deals with the variability of operating conditions and uncertainty caused by modeling errors. They are considered as random uncertainties without any assessment on their distribution. The ranges of variations of uncertain variables and parameters used in this study are given in Table 3 . According to the analysis proposed by Chen [30], we denote noise factors as uncontrollable parameters (Type I), and inherent variations of design variables as control factor (Type II).

Fluctuations during operating phases of flash evaporators are due to variations of inlet temperatures and mass flow rates of liquids (product and coolant) which can dramatically impact the quality of vintage by shifting its nominal output temperature and final alcoholic volume fraction from the target value. The temperatures variations of the must and coolant are supposed to be up to $\pm 1^{\circ} \mathrm{C}$ around their nominal values. As the flash evaporator had been originally designed to concentrate $10 \mathrm{t} / \mathrm{h}$ of must, the inlet product flow rate can vary of $\pm 1 \mathrm{t} / \mathrm{h}$ from the initial value depending on the size of the vineyard.

Moreover, heat transfer coefficients values are derived from experimental correlations that are highly sensitive to physical phenomena with values that are difficult to predict. Due to their predominant role in the heat transfer within the condensers, modeling errors affecting heat transfer coefficients may cause significant inaccuracies in the predictions of the nominal performances. We add two other variables $\left(k_{L P}\right.$ and $\left.k_{V L P}\right)$ to assign a variability of $\pm 1 \%$ on these parameters.

In practical terms, the simplest way to deal with uncertainty is to introduce stochastic variability during the evaluation of candidate solutions. Thus, it is equivalent to 
Table 3. Uncertainties in operating and modeling phases of flash evaporators.

\begin{tabular}{lllll}
\hline Type & Variables and parameters & Name & Unit & Variation \\
\hline \multirow{2}{*}{ Control factors $(\boldsymbol{\Delta} \boldsymbol{x})$} & Inlet product temperature & $T_{p i}$ & $\left({ }^{\circ} \mathrm{C}\right)$ & $\pm 1{ }^{\circ} \mathrm{C}$ \\
& Inlet coolant temperature & $T_{c l}$ & $\left({ }^{\circ} \mathrm{C}\right)$ & $\pm 1{ }^{\circ} \mathrm{C}$ \\
& Input product mass flow rate & $q_{p i}$ & $(\mathrm{t} / \mathrm{h})$ & $\pm 1 \mathrm{t} / \mathrm{h}$ \\
Noise factors $(\varepsilon)$ & Heat transfer coefficients & $k_{L P}$ & $\left(\mathrm{~W} \cdot \mathrm{m}^{-2} \cdot \mathrm{K}^{-1}\right)$ & $\pm 1 \%$ \\
& & $k_{V L P}$ & $\left(\mathrm{~W} \cdot \mathrm{m}^{-2} \cdot \mathrm{K}^{-1}\right)$ & $\pm 1 \%$ \\
\hline
\end{tabular}

Table 4. Box-Behnken design (5 factors, 3 levels (respectively $0,-1,+1)$ ).

\begin{tabular}{|c|c|c|c|c|c|}
\hline $\begin{array}{l}\text { Exp. } \\
\#\end{array}$ & $\begin{array}{l}\text { Factors } \\
T_{p i}\left({ }^{\circ} \mathrm{C}\right)\end{array}$ & $T_{c l}\left({ }^{\circ} \mathrm{C}\right)$ & $q_{p i}(\mathrm{t} / \mathrm{h})$ & $k_{L P}(\%)$ & $k_{V L P}(\%)$ \\
\hline $1-4$ & \pm 1 & \pm 1 & 0 & 0 & 0 \\
\hline $5-8$ & 0 & 0 & \pm 1 & \pm 1 & 0 \\
\hline 9-12 & 0 & \pm 1 & 0 & 0 & \pm 1 \\
\hline $13-16$ & \pm 1 & 0 & \pm 1 & 0 & 0 \\
\hline $17-20$ & 0 & 0 & 0 & \pm 1 & \pm 1 \\
\hline $21-24$ & 0 & \pm 1 & \pm 1 & 0 & 0 \\
\hline $25-28$ & \pm 1 & 0 & 0 & \pm 1 & 0 \\
\hline 29-32 & 0 & 0 & \pm 1 & 0 & \pm 1 \\
\hline $33-36$ & 0 & \pm 1 & 0 & \pm 1 & 0 \\
\hline $37-40$ & 0 & \pm 1 & 0 & \pm 1 & 0 \\
\hline 41 & 0 & 0 & 0 & 0 & 0 \\
\hline
\end{tabular}

define and evaluate a neighborhood around the nominal design configuration such as:

$$
\widetilde{y}=\phi(\widetilde{x}, \varepsilon), \quad \widetilde{x}=x+\Delta x
$$

where $\widetilde{y}$ is the vector of disturbed observation variables computed from the vector of design variables $\boldsymbol{x}$ submitted to the variations of noise factors $\boldsymbol{\varepsilon}$ and control factors $\boldsymbol{\Delta} \boldsymbol{x}$. In nominal evaluation, every combination of design variables results in a unique set of performances. The variability propagated through the behavior model of the flash evaporator towards observation variables results in a set of different functioning states characteristic of one candidate solution.

The analysis of the effects of design variable variations on the performances mainly depends on the method used to simulate uncertainty. In general, uncertainty can be introduced in the simulation model through Monte Carlo simulation, Taylor series expansion or experimental design tables [44]. In our approach, we use the third method. We use a Box-Behnken design ( 5 factors, 3 levels) to sample the domain of noise and control factors as shown in Table 4. Box-Behnken design is an economical fractionalized design, useful while it is expensive to perform the necessary experimental runs. Therefore, 41 experiments are required to evaluate the dispersion of the performance. The choice of a fractional design enables to achieve a homogenous repartition of the experiments around the nominal, and thus a suitable representation of the observation variables excentration. Initially, design of experiments is used to derive a numerical model of the system behavior. It is not the purpose of our approach. Instead, we use design of experiments only for defining a set of points to be evaluated.

\subsection{Measures of performance sensitivity}

Facing with epistemic uncertainties, the calculations of the average performance and standard deviation appear of little interest. Instead, we propose three other measures to qualify the sensitivity of the performances. They are respectively the bandwidth of variation $(\alpha)$, the tolerance to nominal $(\beta)$ and the minimum admissible value $(\gamma)$. Every measure is applied to the observation variables $y_{1}, y_{2}$ and $y_{3}$ (i.e., the output product temperature, the final alcoholic volume fraction and the pressure inside the VLP stage). The measures of the performance sensitivity are presented below.

\subsubsection{Bandwidth of variation}

The bandwidth of variation $(\alpha)$ is the distance between the extreme values achieved for the observation variable disturbing design variables. It corresponds to the maximum range of variation to be expected for the performance. 
a)

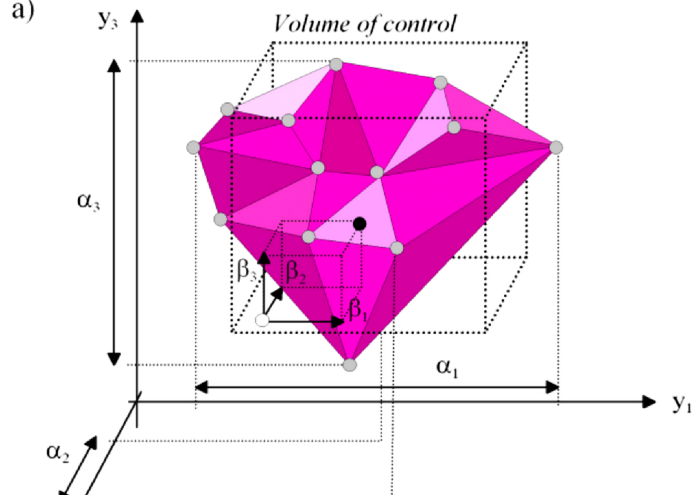

b)

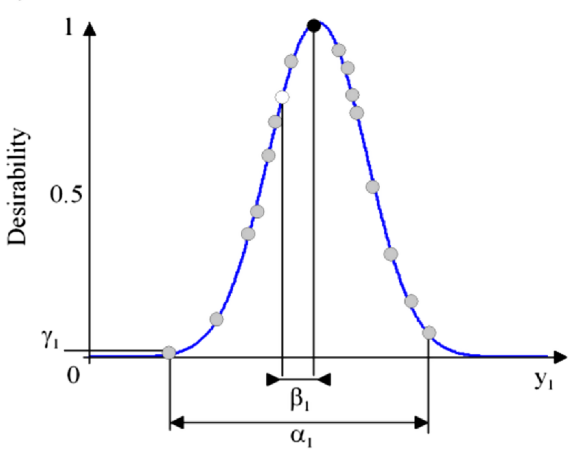

legend: - Nominal solution $\bigcirc$ Neighbour solutions $\bigcirc$ Gravity center

Fig. 5. Representation of the performance sensitivity measures.

This measure is expected to be minimized and is defined as:

$$
\alpha_{i}=\left|\max \left(\widetilde{y}_{i}\right)-\min \left(\widetilde{y}_{i}\right)\right|
$$

This measure is equivalent to define an interval of confidence around the target value to be satisfied. For example, the temperature of the outlet product is expected to be changed of less than $1{ }^{\circ} \mathrm{C}$.

\subsubsection{Tolerance to nominal}

The tolerance to nominal $(\beta)$ measures the eccentricity of the nominal. It is dedicated to replace the nominal performance value toward the center of its interval of variation which can be seen as the center of gravity of the neighborhood (cf. Fig. 5a). This measure is also submitted to minimization and is expressed as:

$$
\beta_{i}=\left|y_{i}-y_{i}\right|, \quad y_{i}=\operatorname{mean}\left(\widetilde{y}_{i}\right)
$$

\subsubsection{Minimum admissible value}

For a given performance, the minimum admissible value $(\gamma)$ is the smallest desirability scores among the neighbor solutions:

$$
\gamma_{i}=\min \left(d\left(\widetilde{y_{i}}\right)\right)
$$

This measure is related to a reliability approach since it constrains performance variations to remain in the range of admissible values. The minimum of the desirability scores is subjected to be maximized.

Figures $5 \mathrm{a}$ and $5 \mathrm{~b}$ give an insight of the sensitivity measures in a $3 \mathrm{~d}$ space. The convex hull formed by the set of tested points is represented. The sensitivity measures are evaluated through a set of constraints which is equivalent to the definition of a volume of control around the nominal performance. Thus, the objective is to keep the performance dispersion within this volume of control.

\subsection{Design objective of sensitivity}

In the same way that we explain the performance criteria into desirability functions, the different sensitivity mea- sures are turned into objectives by specifying relevant desirability functions specifications. The observation variables concerned by the minimization of their variability are related to the vintage quality, i.e. the output temperature of the must, the final alcoholic volume fraction and the pressure in the low pressure chamber. Criteria and desirability function specifications are given in Table 5. In the same way, we have represented the design objective of performance (cf. Fig. 4) the formulation of the sensitivity objective is summarized in graph form in Figure 6.

The design objectives are: (i) limit the bandwidth of variation, (ii) limit the distance of the nominal value to the centre of gravity and (iii) increase the minimum admissible value. The resulting DOIs are computed by taking the minimum of the desirability values. According to the axioms of the MoI [41], this aggregation function is also considered as design appropriate. In [45], this function is used to aggregate desirability functions. The GDI related to design sensitivity results from a geometric mean aggregation of the DOIs:

$$
\begin{aligned}
& G D I_{\text {sens }}=\prod_{i=1}^{3} \widetilde{D O I}_{i}^{v_{i}}, \quad v=\left[\frac{4}{10}, \frac{4}{10}, \frac{2}{10}\right]^{T} \\
& \text { with, } \\
& \widetilde{D O I_{1}}=\min _{\begin{array}{l}
i \\
j=1 \ldots 3
\end{array}}\left(\widetilde{d}_{i}\left(\alpha_{j}\right)\right) \\
& \widetilde{D O I}_{2}=\min _{\begin{array}{l}
i=4 \ldots 6 \\
j=1 \ldots 3
\end{array}}\left(\widetilde{d}_{i}\left(\beta_{j}\right)\right) \\
& \widetilde{D O I_{3}}=\min \begin{array}{r}
i=7 \ldots 9 \\
j=1 \ldots 3
\end{array}\left(\widetilde{d}_{i}\left(\gamma_{j}\right)\right)
\end{aligned}
$$

The min aggregation function enables to improve the lowest desirability value to the expense of the global desirability level of the design solution. Inversely, the weighted geometric mean aggregation reflects the intention of improving the global level of desirability by worsening the lowest desirability value. 
Table 5. Desirability functions specification for the performance sensitivity measures.

\begin{tabular}{|c|c|c|c|c|c|c|c|c|}
\hline \multirow[t]{2}{*}{$\begin{array}{l}\text { Design objectives } \\
\widetilde{D O I}=\left[\widetilde{D O I}_{1}, \ldots, \widetilde{D O I}_{3}\right]^{T}\end{array}$} & \multirow[t]{2}{*}{$\begin{array}{l}\text { Observation } \\
\text { var. } \widetilde{y}=\left[\widetilde{y_{1}}, \ldots, \widetilde{y_{3}}\right]^{T}\end{array}$} & \multirow[t]{2}{*}{ Name } & \multirow[t]{2}{*}{ Unit } & \multicolumn{5}{|c|}{$\begin{array}{l}\text { Desirability functions } \\
\text { specifications } \widetilde{d}=\left[\widetilde{d}_{1}, \ldots, \widetilde{d}_{9}\right]^{T}\end{array}$} \\
\hline & & & & $\mathrm{AC}$ & $\mathrm{d}(\mathrm{AC})$ & SL & $\mathrm{d}(\mathrm{SL})$ & Objective \\
\hline \multirow{4}{*}{ 1) Bandwidth of variation: } & Output temperature & $\alpha_{1}$ & $\left({ }^{\circ} \mathrm{C}\right)$ & 1 & 0.01 & 6 & 0.9 & Minimize \\
\hline & Alcoholic volume fraction & $\alpha_{2}$ & $(\%)$ & 1 & 0.01 & 4 & 0.9 & Minimize \\
\hline & Pressure & $\alpha_{3}$ & (mbar) & 10 & 0.01 & 40 & 0.9 & Minimize \\
\hline & Output temperature & $\beta_{1}$ & $\left({ }^{\circ} \mathrm{C}\right)$ & 0.25 & 0.01 & 2.5 & 0.9 & Minimize \\
\hline \multirow[t]{4}{*}{ 2) Tolerance to nominal: } & Alcoholic volume fraction & $\beta_{2}$ & $(\%)$ & 0.05 & 0.01 & 1.25 & 0.9 & Minimize \\
\hline & Pressure & $\beta_{3}$ & (mbar) & 5 & 0.01 & 20 & 0.5 & Minimize \\
\hline & Output temperature & $\gamma_{1}$ & $\left({ }^{\circ} \mathrm{C}\right)$ & 20 & 0.05 & 25 & 0.9 & \\
\hline & & & & 35 & 0.05 & 30 & 0.9 & Target \\
\hline \multirow{3}{*}{ 3) Minimum admissible: } & Alcoholic volume fraction & $\gamma_{2}$ & $(\%)$ & 11 & 0.05 & 11.8 & 0.9 & \\
\hline & & & & 13 & 0.05 & 12.2 & 0.9 & et \\
\hline & Pressure & $\gamma_{3}$ & (mbar) & 97 & 0.01 & 94 & 0.9 & Minimize \\
\hline
\end{tabular}

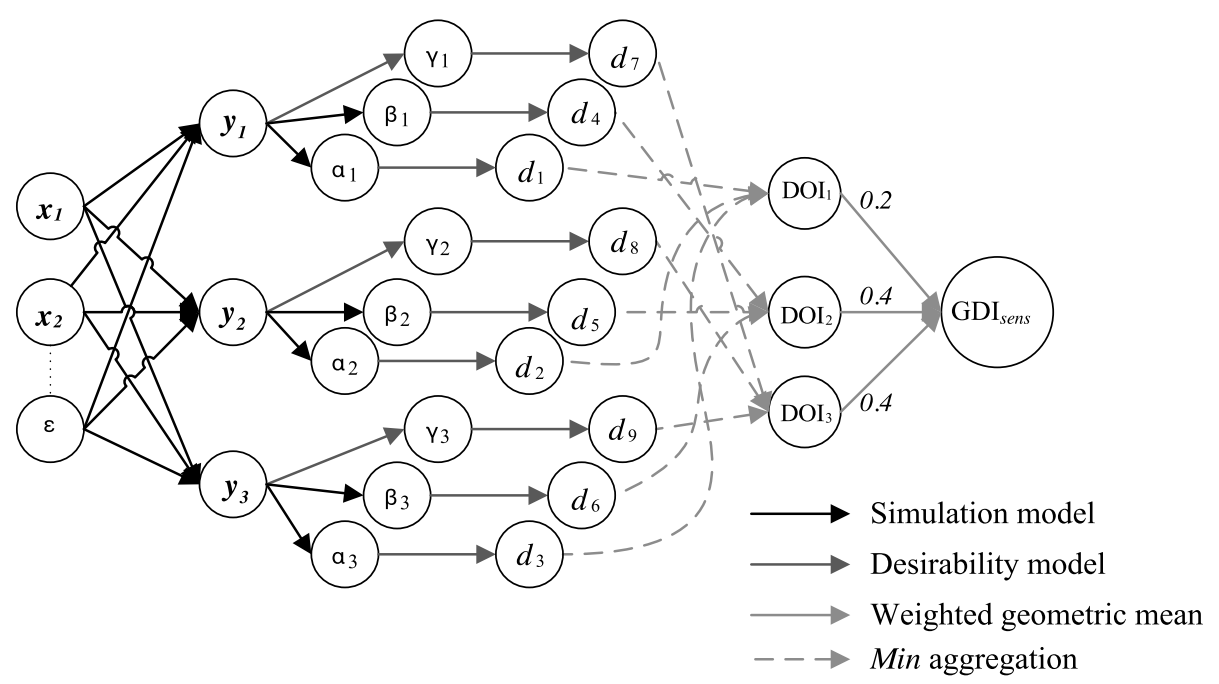

Fig. 6. Formulation of the sensitivity design objective.

\section{Numerical solving}

\subsection{Formulation of the robust design optimization model}

Fundamental basis of multiobjective problems (MO) are presented by Coello [46] and Miettinen [47]. In this section, only the main principles of $\mathrm{MO}$ problems are described. In general, MO problems can be formally expressed as:

$$
\begin{aligned}
& \text { minimize } f(x)=\left[f_{1}(x), f_{2}(x), \ldots, f_{k}(x)\right]^{T} \\
& \text { Subject to: } \\
& g_{i}(x) \geq 0 \quad i=1,2, \ldots, m \\
& h_{i}(x)=0 \quad i=1,2, \ldots, p \\
& x \in \Omega, \quad x=\left[x_{1}, x_{2}, \ldots, x_{n}\right]^{T}
\end{aligned}
$$

where $\boldsymbol{x}$ designates the vector of design variables (or decision variables) taken in the design space $\Omega, f$ is the vector of objective functions to be jointly optimized, $g_{i}$ and $h_{i}$ refer respectively to the $m$ inequality and $p$ equality constraints to be satisfied.

Principles of MO are different from classical monoobjective approaches. Indeed, the main objective of a mono-objective optimization is to find the global optimum solution, i.e. the one which minimizes (or maximizes) the objective function. However, real life applications often involve more than one objective (minimization of the mass, minimization of costs, etc.). Moreover, these objectives are often in conflict, making impossible the determination of a unique optimal solution, but rather a set of equivalent solutions which must be traded-off. When at least two conflictual objectives are traded-off, the classical meaning of optimum is no longer adapted. Instead, the terminology Pareto optimum is generally used.

A vector of variables $\boldsymbol{x}^{*} \Omega$ is said Pareto optimal if $\forall \boldsymbol{x}$ $\Omega, i I=\{1,2, \ldots, k\}$, such as $f_{i}(\boldsymbol{x})=f_{i}\left(\boldsymbol{x}^{*}\right)$, then $\exists j I$ such as: $f_{j}(\boldsymbol{x})>f_{j}\left(\boldsymbol{x}^{*}\right)$. Instead of determining a unique solution, MO provides a set of Pareto optimal solutions. Every 
solution of this set is optimal as it is impossible to reach any solutions which are better simultaneously for every objective.

The determination of the Pareto frontier is based on the notion of dominance between solutions. Let us consider two candidate solutions, denoted $\mathrm{A}$ and $\mathrm{B}$, then $\mathrm{A}$ dominates $\mathrm{B}$ if and only if: $\forall i I=\{1,2, \ldots, k\}, f_{i}(A) \leq f_{i}(B)$ and $\exists j I$ such as: $f_{j}(A)<f_{j}(B)$. If $\mathrm{A}$ dominates $\mathrm{B}$, then it is said that $\mathrm{B}$ is dominated by A, or A is non-dominated by B. Therefore, Pareto optimal solutions are also denoted as nondominated solutions. The set of Pareto optimal solutions, or non-dominated solutions, defines the Pareto frontier. Figure 7 shows a non convex Pareto frontier for a biobjectives minimization problem. Solutions in black represent the set of non-dominated solutions. Using the principle of dominance, the set of dominated solutions can be ordered by defining sub-optimal Pareto frontiers. These solutions are designated as weakly Pareto optimal. Thus, solutions in dark grey represent the solutions which are simultaneously dominated by $\mathrm{A}$ and $\mathrm{B}$, and not dominated by $\mathrm{D}$, whereas solutions in light gray are solutions which are dominated both by A, B and C.

In this study, a design is considered as robust if it achieves a satisfying level of performance while maintaining a low level of variability under uncertainty. This is expressed mathematically with a statement similar to equation (5.1.1) in which the objectives functions are replaced by the $\mathrm{GDI}_{\text {perfo }}$ and $\mathrm{GDI}_{\text {sens. }}$. We can therefore obtain a robust design of two-stage flash evaporator by solving the following bi-objective optimization problem:

$$
\begin{aligned}
& \operatorname{maximize} G D I(x)=\left[G D I_{\text {perfo }}(x), G D I_{\text {sens }}(x)\right]^{T} \\
& \text { Subject to: } \quad x \in \Omega, \quad x=\left[x_{1}, x_{2}, \ldots, x_{6}\right]^{T}
\end{aligned}
$$

One can notice that design constraints are no longer explicit but intrinsic to the design problem definition. Due to discontinuities within the response surface and numerous local extrema created by weighted aggregations, classical gradient-based optimization approaches appear inadequate, and thus, this MO problem is numerically solved by genetic algorithm which enables a global investigation of the design space.

\subsection{Genetic algorithms and NGSAII}

Genetic algorithms (GA) are metaheuristic used to solve non-trivial optimization problems. They simulate the natural selection process of individuals in an unfavorable environment. The survival of the fittest [48] states that within a population, the most adapted individuals tend to live long enough to breed whereas the weakest tend to disappear. By analogy with the natural evolution rules, GA consists in making a population of candidate solutions to evolve toward the optimum. An individual corresponds to a candidate solution of the optimization problem. The quality of each individual is evaluated through a fitness function (the function to be optimized). The best individuals of the current population are first selected by comparison of their fitness scores, and then, a new

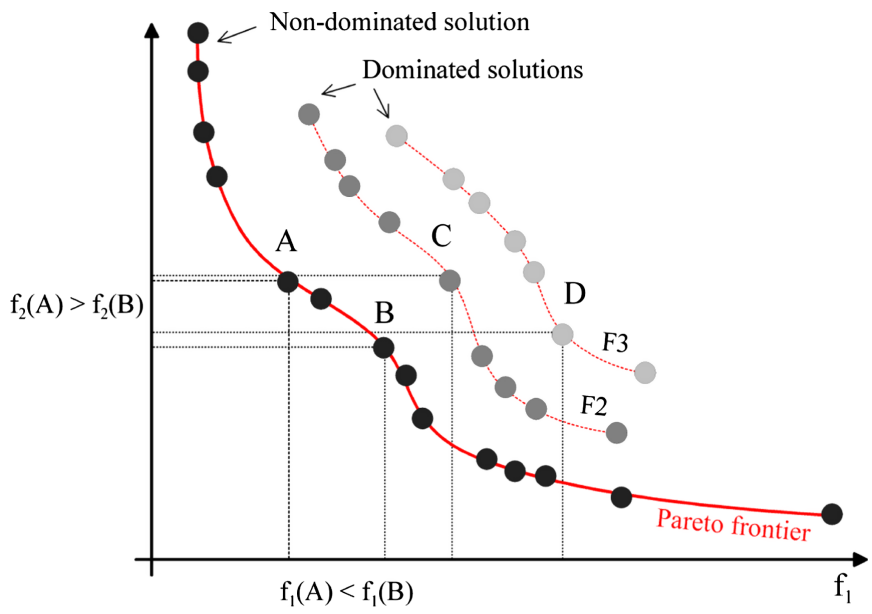

Fig. 7. Pareto frontier and dominance relation for a bi-objective minimization problem.

population of solutions is created for the next generation by crossover and mutation operations. This process is performed generation after generation, until the termination criteria is reached (the maximum number of iterations for example).

According to Deb [49], most of GA developed for MO problems must ensure the convergence toward the Pareto frontier with a uniform repartition of the non-dominated solutions. The NSGA-II (Non Dominated Sorting Genetic Algorithm) developed by Deb [50] is a popular GA for MO. It's a very effective algorithm due to the elitist approach which enables to keep the best individuals from a generation to another. It uses a selection procedure based on non-dominance principle and it requires no parameters specification. It uses a comparison operator based on the computation of crowding distance.

A schematic description of NGSAII principles is represented in Figure 8. A parent population $P_{t}$ of size $N$ and a children population $Q_{t}$ of size $N$ are gathered into a population $R_{t}$ of size $2 N$ (as usual). This operation enables to apply elitist strategy. Individual of the resulted population $R_{t}$ are sorted according to a non-dominance criteria to identify the different frontiers $F_{i}$. Each individual is assigned with a rank (fitness) value based on the front they belong to. Thus, the best individuals will belong to the first frontier (fitness value of 1 ). In addition to the fitness value, a crowding distance is calculated for each individual. The crowding distance is a measure of how close an individual is to its neighbors. It is computed according to the perimeter formed by its closest neighbors on each objective. Large average crowding distance results in better diversity within the population. Parents are selected from the population by using binary tournament selection based on the rank and crowding distance. A new children population is then created by genetic operators (crossover and mutation). In [51], the Simulated Binary Crossover (SBX) and the Polynomial Mutation are proposed as realcoded GA's operators.

The flash evaporators' robust design problem (Eq. (5.1.2)) had been addressed by NGSAII with a population of 250 individuals and a limit criterion of 200 


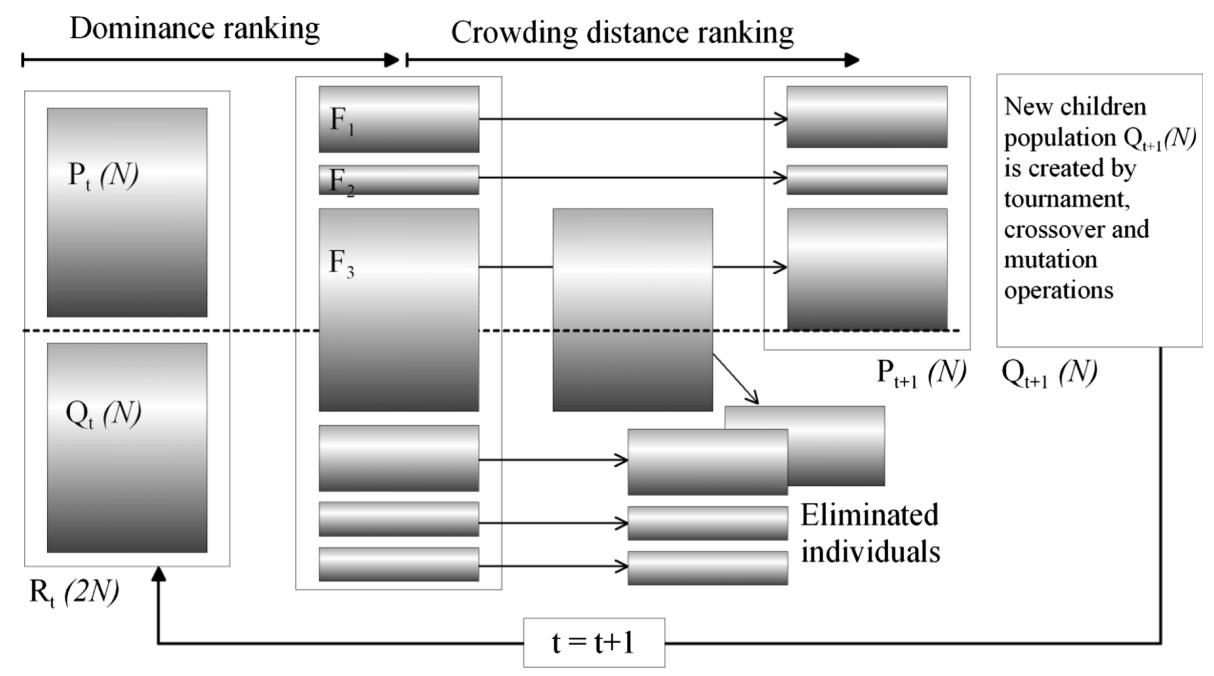

Fig. 8. NGSA-II principles (Deb 2002).

generations. We use the real-coded GA operator with a distribution index of 20. The fitness computation procedure is represented in the flow chart of Figure 9. Results are presented and discussed in the following section.

\section{Results and discussion}

The results are summarized from Figure 10 to Figure 14. The Pareto set $\left(\mathrm{GDI}_{\text {perfo }}, \mathrm{GDI}_{\text {sens }}\right)$ in Figure 10 is composed of 250 robust design solutions. The two ends of the frontier respectively correspond to the design solutions with the lowest sensitivity and with the highest level of performance. In the following, we have plotted the design variables, observation variables and desirability levels according to the $\mathrm{GDI}_{\text {perfo }}$ values of the candidate solutions. It is equivalent of plotting the design properties in function of the Pareto optimal solutions.

Looking at the design variables, we notice that the achievement of robust design solutions is mainly concerned with the input product temperature $\left(T_{p i}\right)$, the coolant liquid temperature $\left(T_{c l}\right)$ and the number of plates in the LP condenser $\left(N_{L P}\right)$. The evolution of these three design variables with the $\mathrm{GDI}_{\text {perfo }}$ are reported in Figure 11a, 11b and 11c. The coolant liquid flow rate required is about $12.5 \mathrm{t} / \mathrm{h}$ of water $\left(q_{c l}=5.55 \mathrm{t} / \mathrm{h}, q_{c l+}=6.94 \mathrm{t} / \mathrm{h}\right)$. The VLP condenser is composed by 23 plates $\left(N_{V L P}\right)$. On Figure $11 \mathrm{~d}$, we have also reported the evaporative capacity expressed in liter of water evaporated per hour. Discontinuities are due to the variation of the number of plates in the LP condensers $\left(N_{L P}\right)$ which evolves from 247 to 248 . The validity domain of the flash evaporator thermodynamic model imply a reduction of the condenser heat transfer area to increase the evaporative capacity of the system (improvement of the cooling power), and so its performances. Inversely, the evaporative capacity is required to be slightly decreased to reduce the variability of the product quality. It means that such a system will be able to cool vintage at a lower inlet temperature (decreasing of the cooling power).
The observation variables related to the system's performance and their interpretation into desirability scores are represented in Figure 12. The desirability scale is placed on the right axis. As the achievement of the product quality objective is highly prioritized (numerical weight of 0.5 ) in the geometric mean aggregation, the performance optimization is mainly driven by the output product temperature $\left(T_{p o}\right)$, the final alcoholic volume fraction $\left(D_{p_{o}}\right)$ and the pressure inside the VLP stage $\left(P_{V L P}\right)$. Consequently, these three performance measures get very high desirability levels (higher than 0.95). The satisfaction of the final alcoholic volume fraction criterion is linked to the evaporative capacity of the system by equation (2.3.2). To reduce the variability of the product quality, the performance of the evaporator must be decreased. Its evaporative capacity is smaller, and consequently the design solution moves away from the target objective being realized. The high prioritization of the quality objective also requires an increase of the cooling power, and therefore of the systems' overall dimensions. Thus, the reduction of the performance variability leads to design solutions which are more transportable. As a consequence, the energy consumptions and overall costs are reduced. These results strongly depend on the weight assignment values used in the aggregation formula. The evolution of the design objectives indexes with the $\mathrm{GDI}_{\text {perfo }}$ are represented in Figure 14.

The measures related to the design sensitivity $\left(\alpha_{i}, \beta_{i}, \gamma_{i}\right)$ are represented in Figure 13. The desirability scores associated to $\alpha_{i}$ and $\beta_{i}$ have also been represented $\left(\gamma_{i}\right.$ is already expressed as a desirability value). According to Figures 13c, $13 \mathrm{f}$ and 13i, the variation of the pressure inside the VLP chamber is not significant and remains acceptable. However, the dispersions of the output temperature and final alcoholic volume fraction are significant. From the variability of the inlet flow rates and temperatures, it results a bandwidth of variation of $3.4^{\circ} \mathrm{C}$ for the outlet product temperature $\left(\alpha_{1}\right)$ and $2.48 \%$ for the final alcoholic volume fraction $\left(\alpha_{2}\right)$. Looking at the tolerance to nominal measure $(\beta)$, it appears that the dispersions of these two variables remain close to the nominal value. Finally, the 


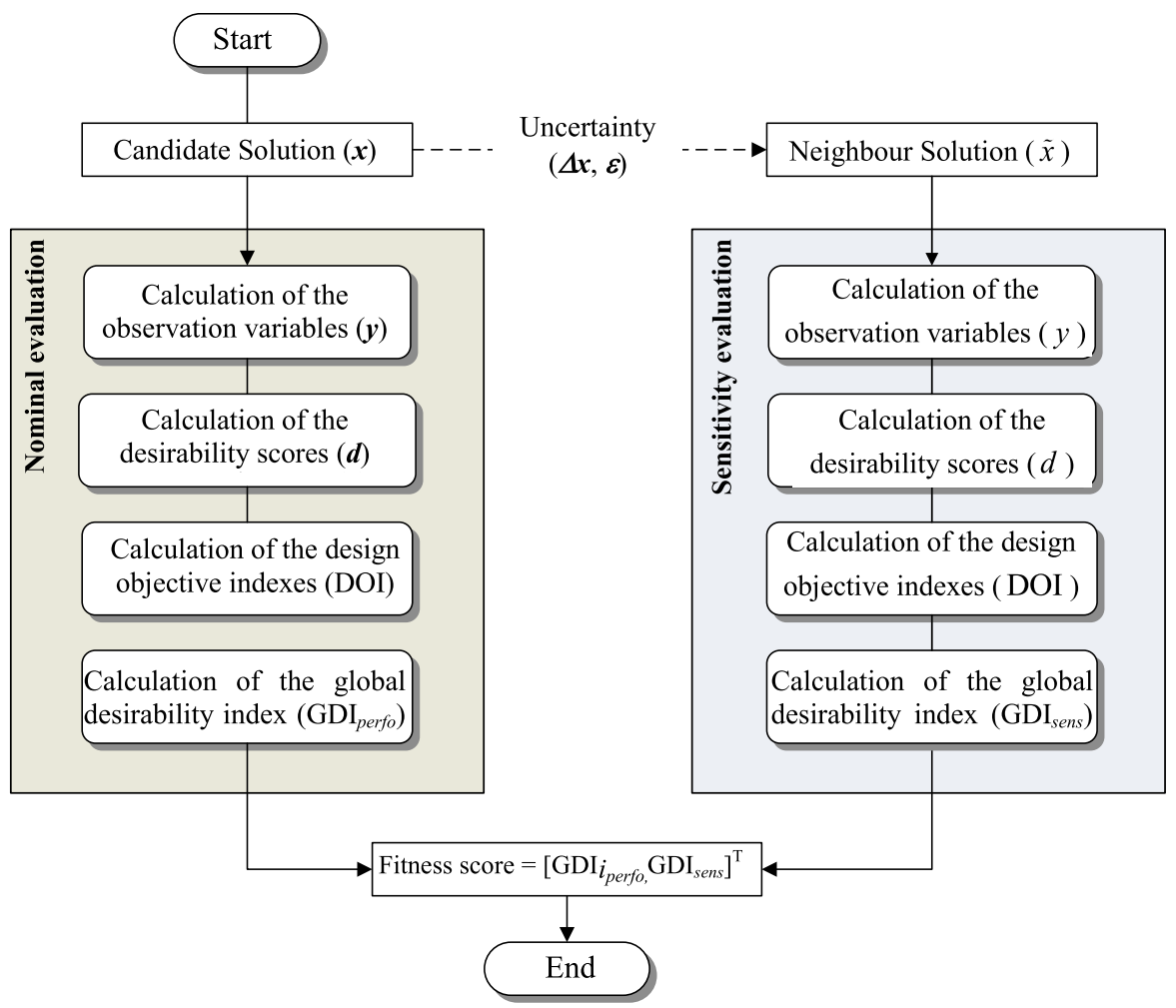

Fig. 9. Fitness computation procedure.

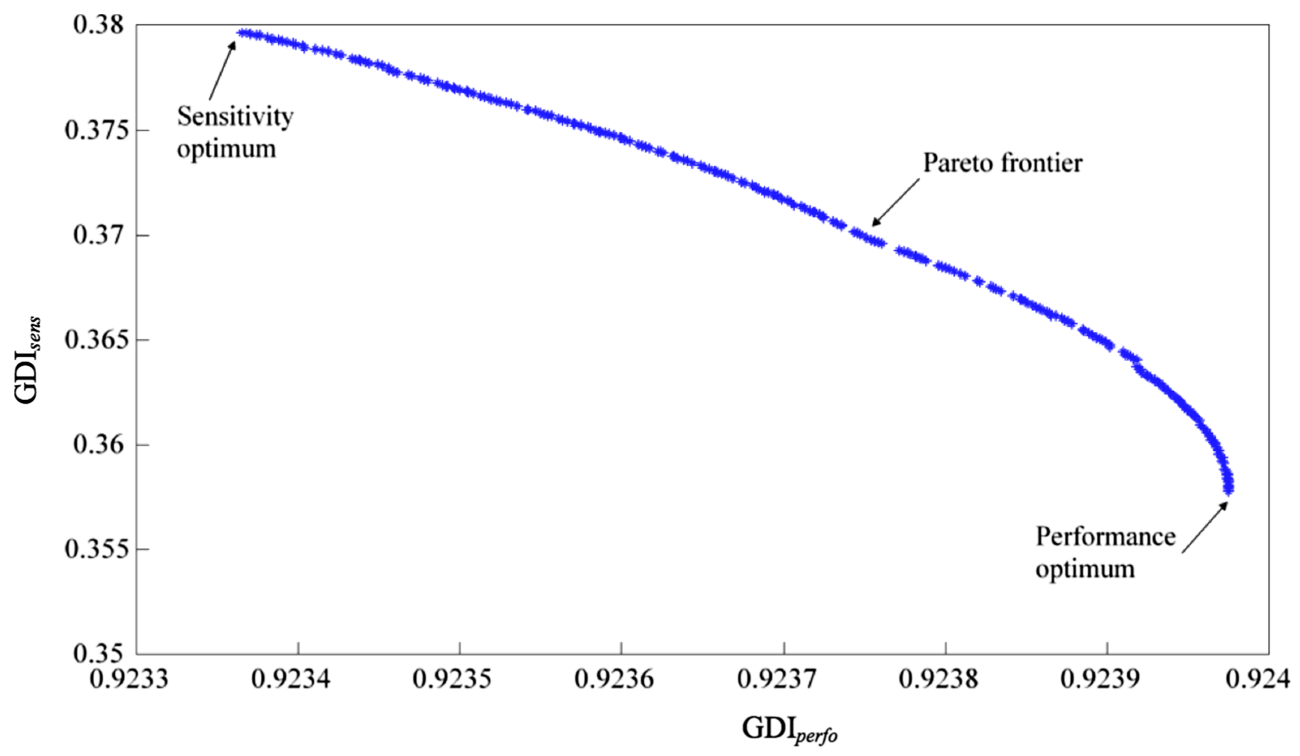

Fig. 10. Pareto set for the robust design problem of flash evaporator.

minimum admissible measure $(\gamma)$ shows that the variability of the final alcoholic volume fraction can lead to undesirable results, i.e. solutions with a desirability level lower than $10^{-2}$. The variability of $T_{p o}$ and $D_{p o}$ tend to be reduced by design solutions with a lower level of performances. The design objective indexes related to the design sensitivity are represented in Figure 14.

According to the robust design problem definition, the sensitivity of the quality product face to external uncertainty can be slightly reduced by performing some compromises on the performance. In particular, the cooling power and the evaporative capacity of the system are lower. However, the design objectives linked to the transportability, the environmental impact and the costs are more achieved. The purpose of the following section deals with the selection of the most preferred solution within the Pareto set by performing different trade-off strategies. 

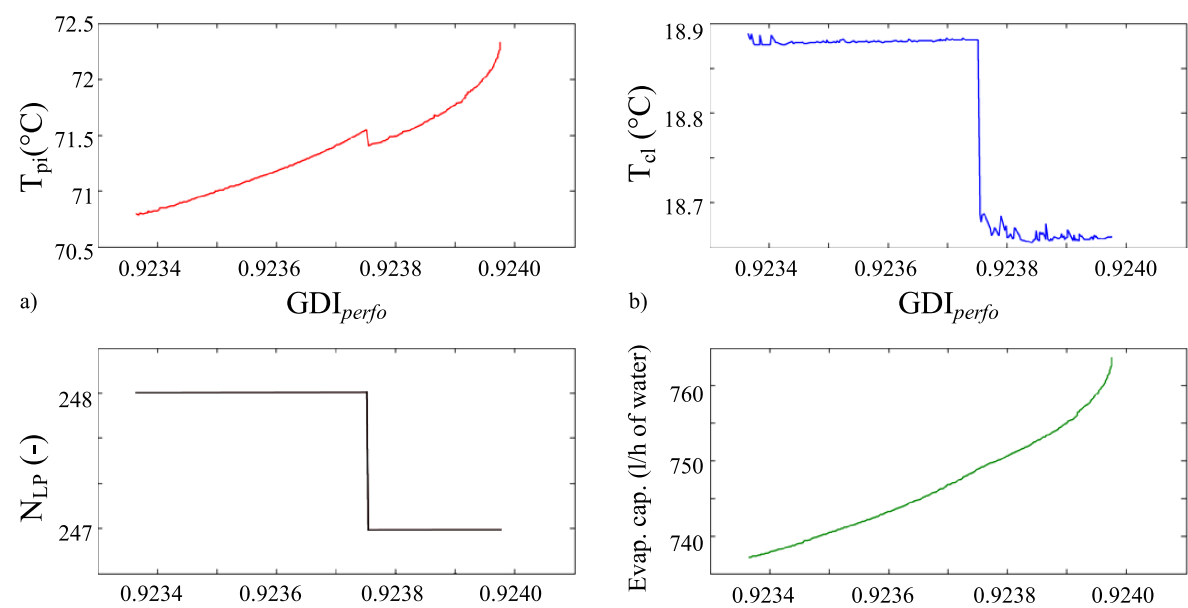

c)

$\mathrm{GDI}_{\text {perfo }}$

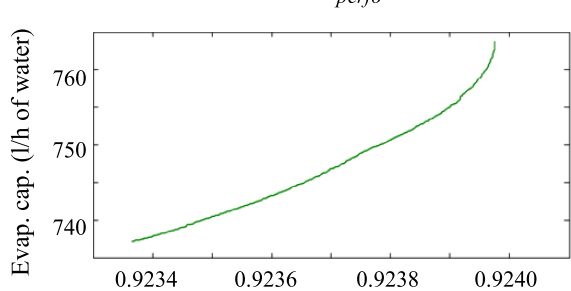

d)

$\mathrm{GDI}_{\text {perfo }}$

Fig. 11. Evolution of design variables along the Pareto frontier.
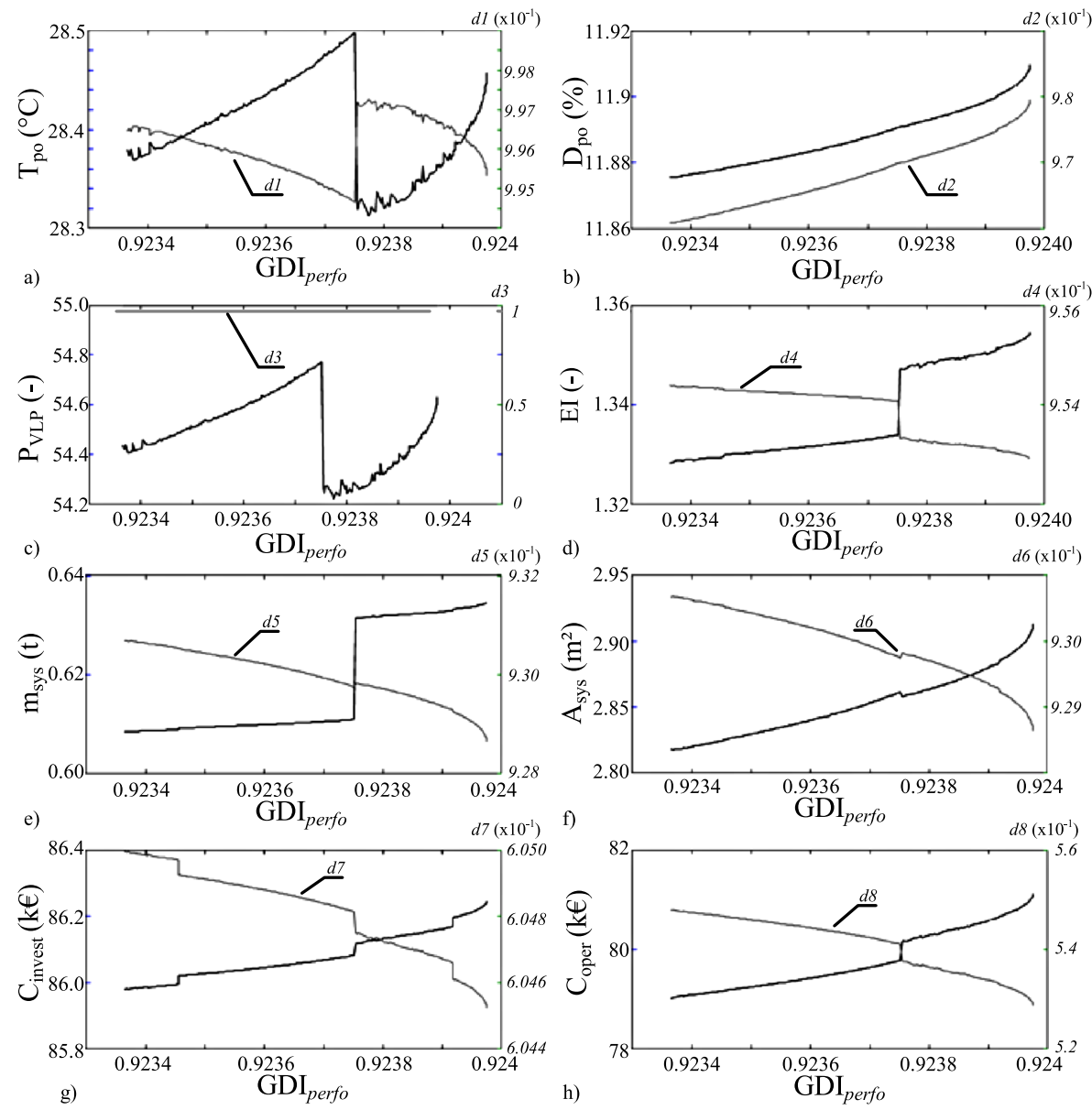

Fig. 12. Evolution of the observation variables and desirability levels along the Pareto frontier.

\subsection{Decision process and trade-off strategies}

The selection of the most preferred design solution depends on the trade-offs strategy which is used by the designer. In the MoI, a class of suitable aggregation functions for modeling trade-offs in engineering is proposed [42]. These functions are derived from the general weighted mean which, in the bi-objective case, is expressed as:

$$
P_{s}\left(f_{1}, f_{2}, w_{1}, w_{2}\right)=\left(\frac{w_{1} f_{1}^{s}+w_{2} f_{2}^{s}}{w_{1}+w_{2}}\right)^{1 / s}, \quad s \in \Re
$$



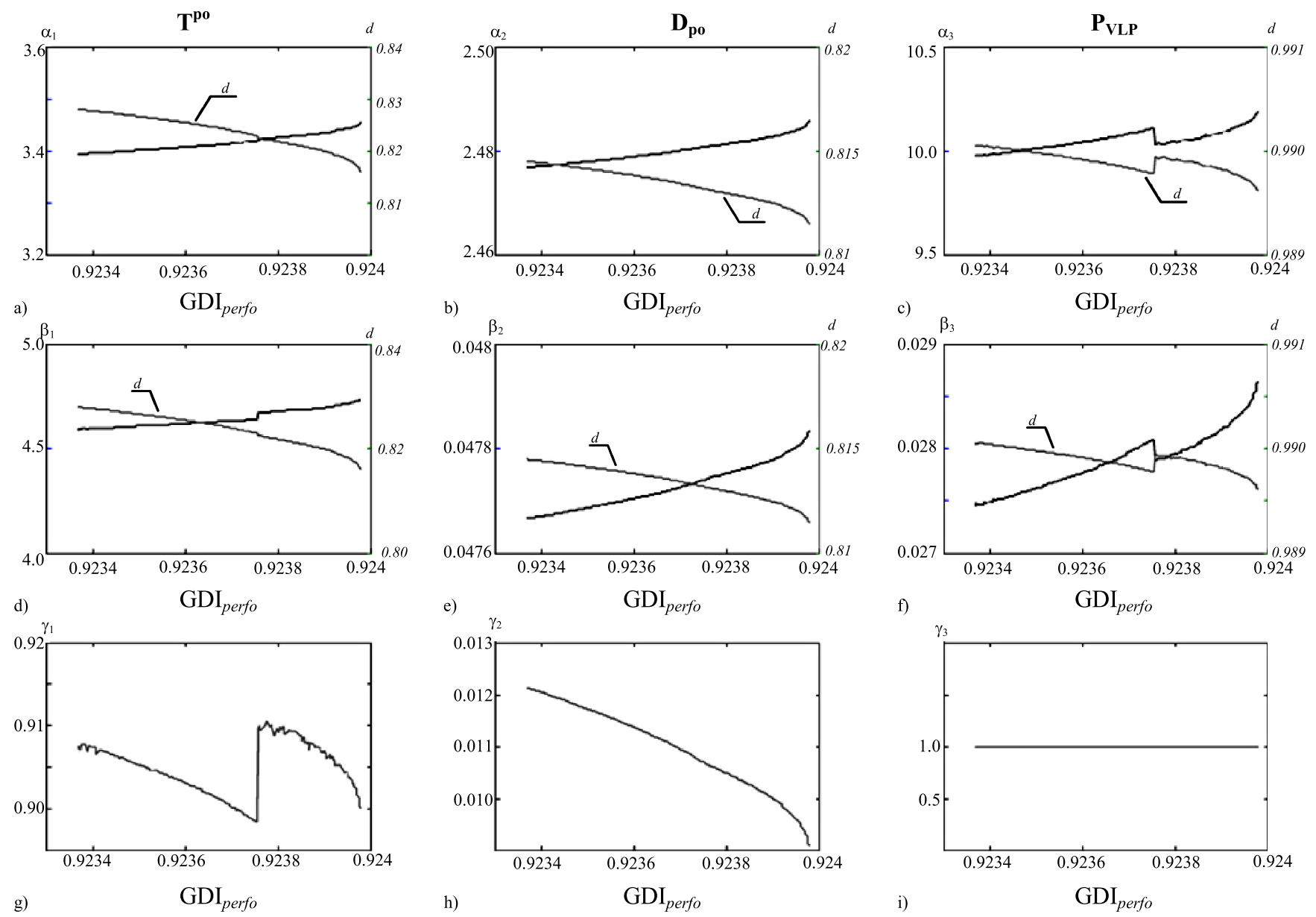

g)

$\mathrm{GDI}_{\text {perfo }}$

h)

Fig. 13. Evolution of the design sensitivity measures along the Pareto frontier.
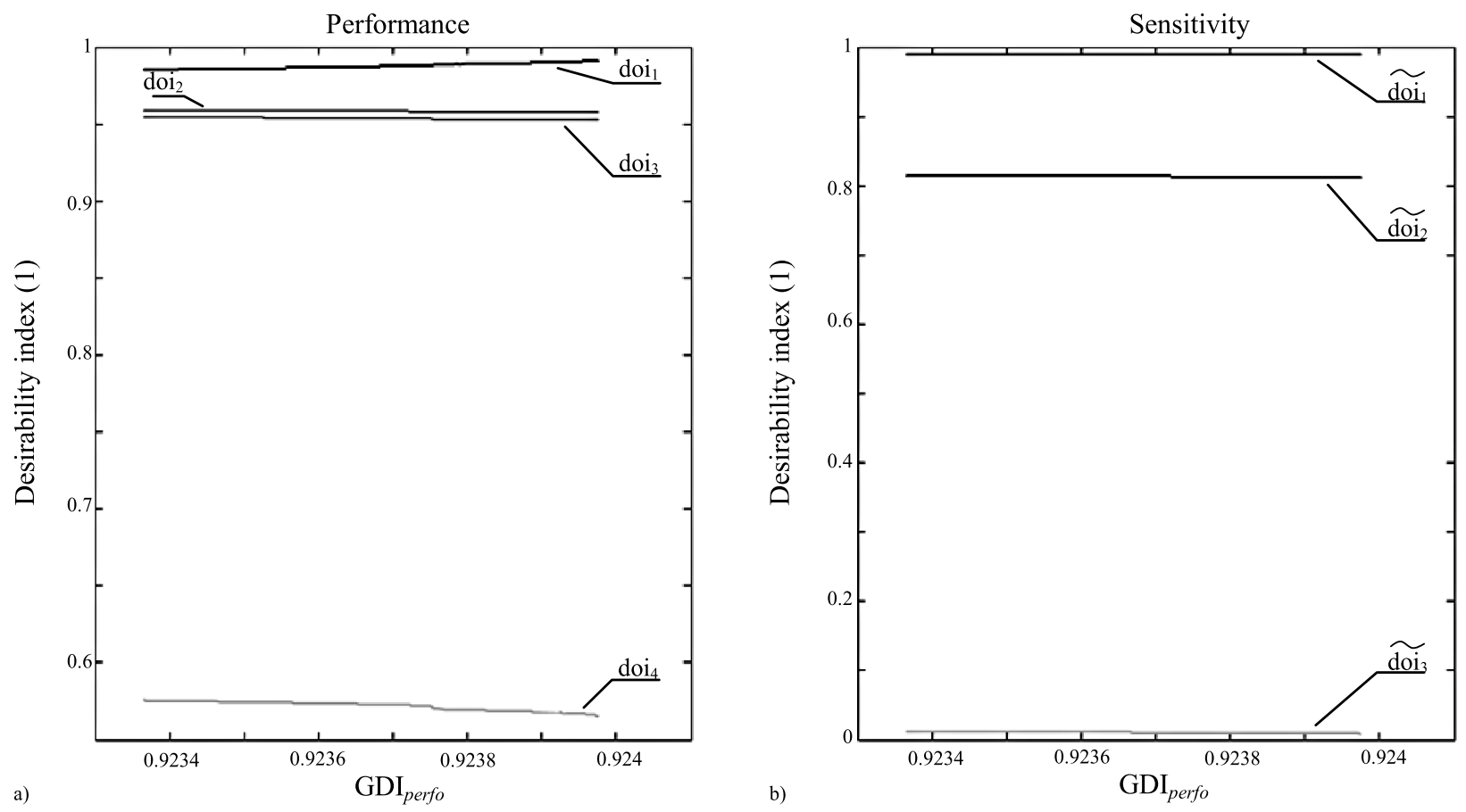

Fig. 14. Evolution of the design objective indexes along the Pareto frontier. 
where the parameter $s$ represents the trade-off strategy. It can be seen as a measure of the compensation level. Increasing the value of $s$ reflects the intention of improving one particular objective by lowering the others. For $s=1$, the aggregation function $P_{1}$ is the classical weighted sum aggregation:

$$
P_{1}\left(f_{1}, f_{2}, w_{1}, w_{2}\right)=\frac{w_{1} f_{1}+w_{2} f_{2}}{w_{1}+w_{2}}
$$

This situation is denoted as a super-compensatory strategy [42]. From equation (6.1), it can be shown [42] that when $s \rightarrow 0$, the aggregation function $\mathrm{P}_{0}$ corresponds to the weighted geometric mean aggregation (cf. Eq. (3.2)) which is a compensatory strategy:

$$
P_{0}\left(f_{1}, f_{2}, w_{1}, w_{2}\right)=\left(f_{1}^{w_{1}} \cdot f_{2}{ }^{w_{2}}\right)^{1 /\left(w_{1}+w_{2}\right)}
$$

In the same way, while $s \rightarrow-\infty$, the function $\mathrm{P}-\infty$ refers to the min aggregation function and traduces a noncompensatory strategy:

$$
P_{-\infty}\left(f_{1}, f_{2}, w_{1}, w_{2}\right)=\min \left(f_{1}, f_{2}\right)
$$

In the following, we discuss the selection of the most preferred design solution on the flash evaporator example according the following strategies: weighted sum aggregation, weighted geometric aggregation, min aggregation.

It is well known that the weighted sum (WS) aggregation suffers from serious drawback due to its inability in detecting solutions in non-convex parts of the Pareto frontier [52,53]. Actually, real Pareto frontiers are rarely completely convex. As a consequence, using a WS aggregation, many of the relevant solutions can't be selected. If we consider the extreme case, i.e. a purely nonconvex Pareto frontier, whatever the weights values, only solutions at the ends could be captured. On Figure 15a, it appears that the WS approach enables to capture 50 solutions over 250 ( $20 \%$ of recovery), using a discretization step of $5 \mathrm{e}^{-6}$ for the weights. For each detectable point, there is a couple of weights such as the solution can be captured [42]. Thus, the designer can filter the Pareto frontier by adjusting the weights value according to its preferences, keeping in mind that many solutions couldn't be selected. Assigning $w_{\text {perfo }}$ with the values $0.95,0.98$ and 0.99 , leads to select solutions with different levels of robustness. Under the threshold value of 0.95 , only the sensitivity optimum is captured.

The weighted geometric (WG) mean aggregation is more effective than the WS aggregation in detecting solutions non-convex parts of the Pareto frontier. However, the capture of the detectable solutions is often hampered by the high sensitivity of the weights approaching the ends of the frontier. On Figure 15b, it appears that 52 solutions are captured over $250(20.8 \%)$ using the same discretization step as the previous case. But, increasing the discretization step of the weights enables to capture more solutions. Assigning $w_{\text {perfo }}$ with the values $0.95,0.98$ and 0.99 , leads to different solutions that the ones achieved with the WS aggregation.

Finally, in Figure 15c, the non-compensatory strategy is applied. As the selection is based on the minimum of the
GDI scores, the sensitivity optimum is captured. Fixing $w_{\text {perfo }}$ to zero and $w_{\text {sens }}$ to one, a WS or WG aggregation leads to the same result.

In Table 6, all found solutions with the different tradeoff strategies are available. For each of them, the values of the design variables are listed. It could be observed that for all captured solutions, the Tpi is closed to $70^{\circ} \mathrm{C}$. This value corresponds to the low value of the range. The temperature of the cooling water is subjected to small variation since the initial value is equal to $20^{\circ} \mathrm{C}$ and the Tcl is around $18.7^{\circ} \mathrm{C}$ (decrease of about $1.5^{\circ} \mathrm{C}$ ). All solutions use an important mass flow rate of water $\left(\mathrm{q}_{\mathrm{cl}}\right.$ and $\left.\mathrm{q}_{\mathrm{cl}+}\right)$ since the operating cost of cooling is a less sensitive criterion than the output temperature of the product (Tpo). This late could be considerate as a relevent parameter of the final product quality.

It could be observed that all solutions have an important number of plates (247 or 248 plates) for the low pressure condenser and a number of plates constituting the very low pressure condenser of 23. It can notice a factor of 10 between these two condensers corresponding to the fact that the cooling need concerns essentially the LP stage. The VLP condenser is only used to adjust the outlet product temperature. The cooling flow rate in the VLP condenser is of the same order of magnitude as the flow added to low pressure condenser $\left(\mathrm{q}_{\mathrm{cl}+}\right)$.

Indeed, the need for cooling in VLP is small compared to the need for cooling LP. More to this point, it is interesting to use a important flow rate of water in the VLP since it will be also used in the LP condenser. This relative important rate allows a good control of the product cooling at the machine output. More generally, the performance of the solutions is high and its sensitivity is low compared to the desirability thresholds. This do not improve a preexisting solution. This leads to a solution improving the value of criteria derived from available information related to actual processes.

\subsection{Recommendations}

From the previous analysis, we derive some recommendations about the robust design of flash evaporators. According to the design requirements, the resulting set of optimal solutions shows a weak gain in sensitivity compared to the loss of performance. Obviously, from the previous section, it appears that a high priority is required on the performance objective $\left(w_{\text {perfo }}>0.95\right)$ to detect potential solutions. As the development of flash evaporators for must concentration applications is mainly concerned with the quality of the product at the system outlet, the evaporative capacity criterion must be fulfilled and thus highly prioritized. The weak values of the design sensitivity objectives are mainly due to the high sensitivity of the final alcoholic volume fraction. Consequently, in the context of this study, we show that an oversized system with a high evaporative capacity appears as the most adapted design to ensure an increase of the alcoholic volume fraction of $1 \%$ while avoiding the degradation of the product quality when the evaporator is moved from an exploitation site to another. 

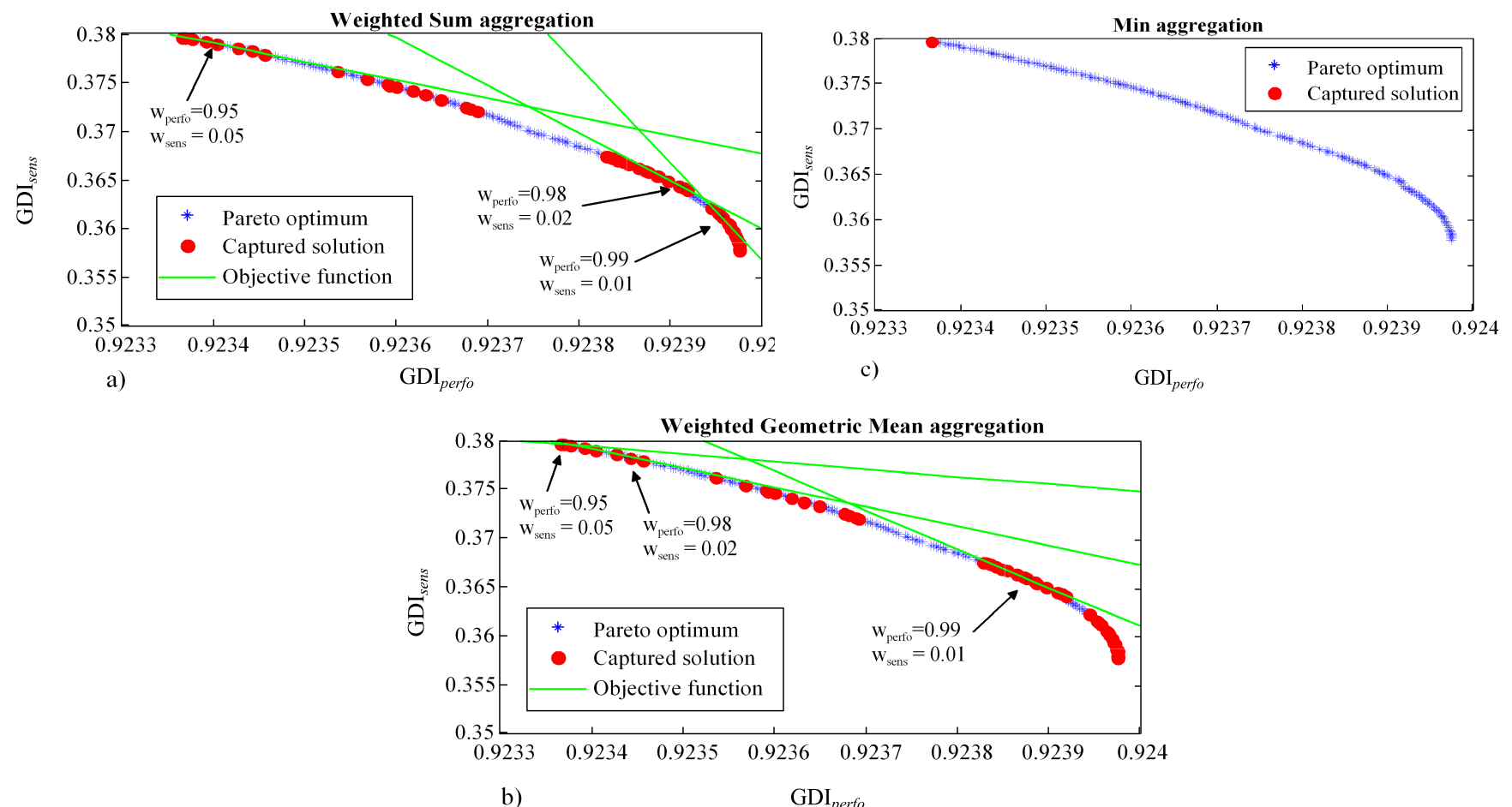

Fig. 15. Selection of the most preferred solution according different trade-off strategies.

Table 6. Optimal design selection with different trade-off strategies.

\begin{tabular}{|c|c|c|c|c|c|c|c|c|c|c|}
\hline \multirow[t]{2}{*}{ Aggregation function } & \multicolumn{2}{|c|}{ Weights } & \multirow[t]{2}{*}{ Selected solution } & \multicolumn{2}{|c|}{ GDI values } & \multicolumn{5}{|c|}{ Design variables } \\
\hline & $\mathrm{w}_{\text {perfo }}$ & $\mathrm{w}_{\text {sens }}$ & & $\mathrm{GDI}_{\text {perfo }}$ & $\mathrm{GDI}_{\text {sens }}$ & $\mathrm{T}_{\mathrm{pi}}\left({ }^{\circ} \mathrm{C}\right)$ & $\mathrm{T}_{\mathrm{cl}}\left({ }^{\circ} \mathrm{C}\right)$ & $\mathrm{q}_{\mathrm{cl}}(\mathrm{t} / \mathrm{h})$ & $\mathrm{q}_{\mathrm{cl}+}(\mathrm{t} / \mathrm{h})$ & $\mathrm{N}_{\mathrm{LP}} \mathrm{N}_{\mathrm{VLP}}$ \\
\hline \multirow{4}{*}{ Weighted sum $(s=1)$} & 0.95 & 0.05 & \#237 & 0.9234 & 0.3790 & 70.83 & 18.88 & 5.55 & 6.94 & $248 \quad 23$ \\
\hline & 0.98 & 0.02 & $\# 56$ & 0.9239 & 0.3643 & 71.81 & 18.66 & 5.55 & 6.94 & $247 \quad 23$ \\
\hline & 0.99 & 0.01 & $\# 27$ & 0.9240 & 0.3612 & 72.06 & 18.66 & 5.55 & 6.94 & 24723 \\
\hline & 0.95 & 0.05 & \#249 & 0.9234 & 0.3796 & 70.79 & 18.88 & 5.55 & 6.94 & $248 \quad 23$ \\
\hline \multirow{2}{*}{$\begin{array}{l}\text { Weighted product } \\
(s=0)\end{array}$} & 0.98 & 0.02 & $\# 226$ & 0.9234 & 0.3783 & 70.89 & 18.88 & 5.55 & 6.94 & $248 \quad 23$ \\
\hline & 0.99 & 0.01 & $\# 70$ & 0.9239 & 0.3659 & 71.69 & 18.66 & 5.55 & 6.94 & 24723 \\
\hline $\min (s \rightarrow-\infty)$ & & & $\# 250$ & 0.9234 & 0.3797 & 70.79 & 18.89 & 5.55 & 6.94 & $248 \quad 23$ \\
\hline
\end{tabular}

\section{Summary and conclusion}

In this research work, a methodology for achieving robust design of flash evaporators for the wine industry has been presented. The developed approach tackles the robust design problem as a trade-off between two main objectives: (i) improve the overall level of performance including the quality of the vintage, the transportability of the system and the total costs; (ii) reduce the sensitivity of some performances, namely the temperature of the outlet product and the final alcoholic volume fraction, under epistemic uncertainty. An originality of the method is to consider uncertainties without probabilistic distributions. We also introduce three measures to observe the dispersion of the performances: the bandwidth of variation, the tolerance to nominal, and the minimum admissible value. A preference aggregation method is used to formulate the two design objectives. The design objective of performance is based on weighted geometric mean aggregations whereas the sensitivity objective involves min aggregations steps. These two aggregation strategies are considered as design appropriate, and thus, enables to reflect accurately the intentions of the designer. The Pareto set of the optimal design solutions is generated by the non-dominated sorting genetic algorithm NGSAII. Finally, the selection of the most preferred solution according to different trade-off strategies has been discussed.

From the robust design formulation and criteria definitions, the methodology enables to show that the variability of the product quality, in particular the vintage output temperature and final alcoholic volume fraction, can be reduced by performing some compromises on the performances. These two observation variables are decisive for the wine quality and their variations must be controlled. 
In this way, the quality product objective has been highly prioritized. Such a strategy coupled with a geometric mean aggregation leads to small improvements of the other objectives. But, another assignment of weight values may lead to different system configurations which can be more robust. Finally, in the last section, we have observed that the selection of the most preferred design solutions can be modeled by a class of function which is more or less compensatory, and thus, the modeling of trade-offs is of main interest. Obviously the designer should be able to express how much he is prepared to loose in performance to reduce the variability of the design. This salient point will be the subject of further development and research works.

\section{Nomenclature}

\section{Physical variables and parameters (associated unit)}

C Energy consumption $(\mathrm{kW} \cdot \mathrm{h})$

$\bar{C} \quad$ Costs $(€)$

Cx Rate of concentration (1)

D Alcoholic volume fraction (\%)

EI Environmental Impact (1)

$h \quad$ Heat transfer coefficient $\left(\mathrm{W} \cdot \mathrm{m}^{-2} \cdot \mathrm{K}^{-1}\right)$

$m$ Mass (t)

$N \quad$ Number of plates within the condensers (1)

$\mathrm{P} \quad$ Pressure $(\mathrm{Pa})$

$q \quad$ Mass flow rate $(\mathrm{t} / \mathrm{h})$

A Floor area $\left(\mathrm{m}^{2}\right)$

$\mathrm{T}$ Temperature $\left({ }^{\circ} \mathrm{C}\right)$

$t \quad$ Time (s)

\section{Decision variables and parameters (associated unit)}

\section{$\stackrel{d}{d} \quad$ Desirability score (1)}

$\widetilde{d} \quad$ Desirability score related to the sensitivity objective (1)

DOI Design Objective Index (1)

$\widetilde{D O I}$ Design Objective Index related to the sensitivity objective (1)

GDI Global Desirability Index

$\boldsymbol{x} \quad$ Vector of design variables

$\widetilde{x} \quad$ Disturbed design variables vector

$\boldsymbol{y}$ Vector of observation variables

$\widetilde{y}_{i} \quad$ Disturbed vector associated to the $\mathrm{i}^{\text {th }}$ observation variable

$\bar{y}_{i} \quad$ Average of the $\mathrm{i}^{\text {th }}$ observation variable values

$\boldsymbol{w} \quad$ Vector of numerical weights

\section{Greek symbols}

$\Omega \quad$ Design space

$\alpha \quad$ Measure of the bandwidth of variation $\beta \quad$ Measure of the tolerance to nominal

$\gamma$ Measure of the minimum admissible value

$\Delta \mathrm{x}$ Variation of control factors

$\varepsilon \quad$ Variation of noise factors

$\sigma \quad$ Standard deviation

$\phi \quad$ Flash evaporator simulation model

\section{Subscripts}

cl Coolant liquid

elec Electric

invest Investment

LP Low pressure

op Operating

perfo Performance

pi Inlet product

po Outlet product

sens Sensitivity

sys System

VLP Very Low Pressure

\section{References}

[1] J.W. Wu, M.J. Biggs, E.J. Hu, Dynamic model for the optimisation of adsorption-based desalination processes, Appl. Therm. Eng. 66 (2014) 464-473

[2] Z. Berk, Food process engineering and technology, 2nd edition, Food science and technology, International Series, Elsevier, 2013, 1-721.

[3] Q. Ruan, H. Jiang, M. Nian, Z. Yan, Mathematical modeling and simulation of countercurrent multiple effect evaporation for fruit juice concentration, J. Food Eng. 146 (2015) 243251.

[4] A.G. Reynolds, Managing Wine Quality: vol. 2 Oenology and Wine Quality, Woodhead Publishing, 2010, 589-630.

[5] D. Ageron, J.L. Escudier, Ph. Abbal, M. Moutounet, Pretreatment of grapes by flash detente under high vacuum atmosphere (Prétraitement des raisins par Flash Détente sous vide poussé), Rev. Fr. Oenol. 153 (1995) 50-54.

[6] J.L. Escudier, et al., Interest traitrement of grapes from high vacuum atmosphere for oenology (Intérêt du traitrement des raisins par un vide poussé pour l'œnologie), ONIVINS, Contrat Etat - Région, filière viti-vinicole, 1995.

[7] J.L. Escudier, M. Mikolajczak, M. Moutounet, Pretreatment of grapes by flash detente under high vacuum atmosphere and wine characteristics (Pré-traitement des raisins par flash détente sous vide et caractéristiques des vins), Journal International des Sciences de la Vigne et du Vin, hors série Traitements Physiques des MoÛts et des Vin (1998) 105110.

[8] E. Vinsonneau, P. Escaffre, Evaluation of winemaking process by flash detente approach in Bordeaux - Synthesis of three years of testing 1999-2001 (Evaluation du procédé de vinification par la flash-détente en bordelais - Synthèse de trois années d'essais 1999-2001), CRAT ITV, France, 2002.

[9] E. Celotti, S. Rebecca, Expériences récentes de thermomacération des raisins rouges, Revue des (Enologues, 87 (1998) 23-28. 
[10] O. Miyatake, K. Murakami, Y. Kawata, T. Fujii, Fundamental experiments with flash evaporation, Heat Transfer Japanese Res. 2 (1973) 89-100.

[11] O. Miyatake, Y. Kito, K. Tagawa, Y. Murata, Transient characteristics and performance of a novel desalination system based on heat storage and spray flashing, Desalination 137 (2001) 157-166.

[12] P. Sebastian, J.P. Nadeau, Experiments and modeling of falling jet flash evaporators for vintage treatment, Int. J. Therm. Sci. 41 (2002) 269-280.

[13] Agreste, Ministry of Agriculture, Food, Fisheries, Rural Affairs and Spatial Planning, Annual Agricultural Statistics, Aquitaine, French, 2010, www.agreste.agriculture.gouv.fr (last access: 18/03/2015).

[14] D. Cadiot, P. Sébastian, D. Callede, J.P. Nadeau, System for cooling a heated juice by partial low-pressure evaporation, Patent WO02096530, 2002.

[15] A. Bouchama, S. Sebastian, J.P. Nadeau, Flash evaporation, modeling and constraints formulation, Transactions on IChemE, 81(Part A) (2003) 1250-1258

[16] V. Ho Kon Tiat, P. Sebastian, J.P. Nadeau, Multicriteriaoriented preliminary design of a flash evaporation process for cooling in the wine industry, J. Food Eng. 85 (2008) 491-508.

[17] V. Ho Kon Tiat, P. Sebastian, T. Quirante, Multiobjective optimization of the design of two-stage flash evaporators: Part 1: Process modeling, Int. J. Therm. Sci. 49 (2010) 2453 2458.

[18] P. Sebastian, T. Quirante, V. Ho Kon Tiat, Multiobjective optimization of the design of two-stage flash evaporators: Part 2: Multiobjective optimization, Int. J. Therm. Sci. 49 (2010) 2459-2466.

[19] M.S. Phadke, Quality Engineering Using Robust Design, $1^{\text {st }}$ edition, Prentice Hall, 1989.

[20] P.J. Ross, Taguchi Techniques for Quality Engineering, $2^{\text {nd }}$ edition, McGraw-Hill Professional, New York, 1995.

[21] G. Taguchi, S. Chowdhury, Y. Wu, Taguchi's Quality Engineering Handbook, $1^{\text {st }}$ edition, Wiley-Interscience, New York, 2004.

[22] J.F. Brotchie, Optimization and robustness of structural engineering systems, Eng. Struct. 19 (1997) 289-292.

[23] D.B. Parkinson, Robust design by variability optimization, Qual. Reliab. Eng. Int. 13 (1997) 97-102

[24] X. Du, W. Chen, Towards a Better Understanding of Modeling Feasibility Robustness in Engineering Design, J. Mech. Des. 122 (2000) 385-394.

[25] M. Ardakani, R. Noorossana, S. Niaki, H. Lahijanian, Robust Parameter Design Using the Weighted Metric Method-The Case of 'the Smaller the Better', Int. J. Appl. Math. Comput. Sci. 19 (2009) 59-68.

[26] C. Zang, M.I. Friswell, J.E. Mottershead, A review of robust optimal design and its application in dynamics, Comput. Struct. 83 (2005) 315-326.

[27] H.G. Beyer, B. Sendhoff, Robust optimization-A comprehensive survey, Comput. Methods Appl. Mech. Eng. 196 (2007) 3218-3190.

[28] M. Arvidsson, I. Gremyr, Principles of robust design methodology, Qual. Reliab. Eng. Int. 24 (2008) 23-35.

[29] G.I. Schuëller, H. Jensen, Computational methods in optimization considering uncertainties - An overview, Comput. Methods Appl. Mech. Eng. 198 (2008) 2-13.

[30] W. Chen, J.K. Allen, A Procedure for Robust Design: Minimizing Variations caused by Noise Factors and Control Factors, J. Mech. Des. 118 (1996) 478-485.
[31] W. Chen, M.M. Wiecek, J. Zhang, Quality Utility-A Compromise Programming Approach to Robust Design, J. Mech. Des. 121 (1999) 179-187.

[32] M. Basseur, E. Zitzler, Handling Uncertainty in IndicatorBased Multiobjective Optimization, Int. J. Comput. Intell. Appl. 2 (2006) 255-272.

[33] D. Greiner, P. Hajela, Truss topology optimization for mass and reliability consideration-co-evolutionary multiobjective formulations, Struct. Multidiscip. Optim. 45 (2011) 589 613.

[34] T. Quirante, Y. Ledoux, P. Sebastian, Multiobjective optimization including design robustness objectives for the embodiment design of a two-stage flash evaporator, Int. J. Interact. Des. Manuf. 6 (2011) 29-39.

[35] P, Jacquet, C. Capdevielle, Installations vinicoles, Tome 2, Transport de la vendange et vinification, Féret, Bordeaux, 2002, 298p.

[36] M. Goedkoop, S. Effting, M. Collignon, The Eco-indicator 99: A damage oriented method for Life Cycle Impact Assessment, Manual for Designers, $2^{\text {nd }}$ edition, Pré Consultants B.V., Amersfoort, The Netherlands, 2000.

[37] S.A. Leeper, Wet Cooling Tower: "Rule-of-Thumb" Design and Simulation, U.S. Department of Energy Assistant Secretary for Ressource Application, Office of Geothermal, under DOE Contract No. DE-AC0776ID01570, 1981.

[38] K. Rehfeldt, B. Schwenk, J.P. Molly, Sensitivity study of different parameters concerning the energy generating costs of wind turbines, in: R. Watson (Eds.), Proceedings of European Wind Energy Conference, Dublin, Ireland 1997, pp. 90-93.

[39] E. Harrington, The Desirability Function, Ind. Qual. Control 21 (1965) 494-498.

[40] G. Derringer, R. Suich, Simultaneous Optimization of Several Response Variables, J. Qual. Technol. 12 (1980) 214-219.

[41] E.K. Antonsson, K.N. Otto, Imprecision in Engineering Design, Special combined issue of the transactions of the ASME commemorating the $50^{\text {th }}$ anniversary of the design engineering division of the ASME 117 (1995) 25-32.

[42] M.J. Scott, E.K. Antonsson, Aggregation Functions for Engineering Design Trade-Offs, $9^{\text {th }}$ International conference on design theory and methodology 2 (1995) 389-396.

[43] T.L. Saaty, Relative measurement and its generalization in decision making: Why pairwise comparisons are central in mathematics for the measurement of intangible factors The Analytic Hierarchy/Network Process, RACSAM (Review of the Royal Spanish Academy of Sciences) 102 (2008) 251-318.

[44] M.N. Shyam, Robust Design, Seminar Report, Department of Aerospace Engineering, Indian Institute of Technology, 2002 .

[45] K.J. Kim, D.K.J. Lin, Simultaneous Optimization of Mechanical Properties of Steel by Maximizing Exponential Desirability Functions, J. R. Stat. Soc. Ser. C Appl. Stat. 49 (2000) 311-325.

[46] C. Coello, et al., Evolutionary Algorithms for Solving MultiObjective Problems, $1^{\text {st }}$ edition, New York, Springer, 2002.

[47] K. Miettinen, Nonlinear multiobjective optimization, United States Of America, Kluwer Academic Publisher, Fourth Printing, 1999.

[48] D.E. Goldberg, Genetic algorithm: exploration, optimisation and automatic learning (Algorithmes génétiques: Explora- 
tion, optimisation et apprentissage automatique), AddisonWesley, France, 1996.

[49] K. Deb, Evolutionary Algorithms for Multi-Criterion Optimization in Engineering Design, Evol. Algorithms Eng. Comput. Sci. 2 (1999) 135-161.

[50] K. Deb, A. Pratap, S. Agarwal, T. Meyarivan, A fast and elitist multiobjective genetic algorithm: NSGA-II, IEEE Trans. Evol. Comput. 6 (2002) 182-197.
[51] K. Deb, R.B. Agarwal, Simulated Binary Crossover for Continuous Search Space, Complex Syst. 9 (1995) 115-148.

[52] R.T. Marler, S.A. Jasbir, The weighted sum method for multi-objective optimization: new insights, Struct. Multidiscip. Optim. 41 (2009) 853-862.

[53] A. Messac, et al., Ability of Objective Functions to Generate Points on Nonconvex Pareto Frontiers, AIAA J. 38 (2000) 1084-1091.

Cite this article as: T. Quirante, Y. Ledoux, P. Sebastian, Robust design of flash evaporators for must concentration applications in wine production, Mechanics \& Industry 19, 207 (2018) 